\title{
Efeitos Diferenciados de Incentivos Fiscais e Financiamentos sobre os Gastos Empresariais em P\&D na Segunda Metade dos Anos 2000
}

\section{Differential Effects of Tax Incentives and Financing on Business R\&D Expenditure in the Second Half of the 2000s}

Paulo César Brigante ${ }^{a}$

\begin{abstract}
Resumo: Tendo em vista o papel dos instrumentos de suporte público à pesquisa e desenvolvimento (PED), enquanto um tema pouco explorado e inconcluso, este artigo tem como objetivo avaliar a eficácia dos incentivos fiscais e financiamentos sobre os gastos empresariais privados nessas atividades. Considerando-se os níveis historicamente insuficientes dos últimos, o Brasil mantém uma distância significativa nos indicadores de inovação em relação aos países avançados. No contexto da retomada de iniciativas de políticas industriais e de inovação nos anos 2000, houve maior aporte de recursos públicos, através do crédito e dos incentivos fiscais, do qual se esperava elevação dos gastos privados em PEBD. A razão principal da intervenção governamental obedecia à lógica de amenizar os elevados custos e riscos da PED. Com a base de microdados da Pesquisa de Inovação (Pintec), do IBGE, neste estudo são realizadas estimativas sobre os efeitos de cada tipo de instrumento, aplicando-se o método de diferenças em diferenças (DID) com covariadas para as bases de 2005, 2008 e 2011 . Dois painéis de períodos consecutivos são construídos: 2005-2008 e 2008-2011, e, com isso, as estimativas mensuram as diferenças de variações de gastos em PËD entre empresas beneficiárias e não beneficiárias. Adicionalmente, a análise foca empresas localizadas em setores de diferentes graus de intensidade tecnológica. Com a escolha do método, procura-se contornar o problema do viés de seleção, constatando-se que os efeitos de adicionalidade limitam-se aos incentivos fiscais, não se generalizando para todos os setores.
\end{abstract}

Palavras-chave: Incentivos fiscais à PESD. Financiamento à PESD. Políticas de inovação.

\begin{abstract}
The debate on the role of public support for research and development (RED) is still a relatively unexplored subject and unfinished, especially in the recent period. This article aims to evaluate the effectiveness of tax incentives and financing on private business spending in these activities. Considering the historically insufficient levels of the latter, Brazil maintains a significant distance in the indicators of innovation in relation to the advanced countries. In the context of the resumption of industrial policy and innovation initiatives in the 2000s, there was a greater contribution of public resources, through credit and fiscal incentives, which were expected to increase private RED expenditures.
\end{abstract}

a Universidade Estadual Paulista (UNESP), Faculdade de Ciências e Letras de Araraquara, Departamento de Economia. Araraquara, São Paulo, Brasil. 
The main reason for government intervention in the programs of these policies obeyed the logic of mitigating the high costs and risks of REDD. With the micro-data base of the Research of Innovation (Pintec), of the Brazilian Institute of Geography and Statistics (IBGE), estimates were made on the effects of each type of instrument applying the Differences in Differences (DID) method with covariates for the bases of 2005, 2008 and 2011. Two panels of consecutive periods were built: 2005-2008 and 2008-2011. Thus, the estimates measured the differences in RED spending variations between beneficiary and non-beneficiary companies. In addition, the analysis focused on companies located in sectors of different degrees of technological intensity. With the choice of method, we tried to overcome the problem of selection bias, noting that the additionality effects were limited to fiscal incentives, not generalizing to all sectors.

Keywords: REDD fiscal tax. RED credit. Innovation policies.

JEL Classification: L52.

\section{1 lntrodução}

Estimular os gastos privados em pesquisa e desenvolvimento (PED) por meio de mecanismos de apoio público tem sido um dos objetivos dos programas governamentais de incentivo à inovação em vários países. No ano de 2000 as empresas da indústria de transformação no Brasil destinaram 1,88\% do faturamento líquido às atividades de PEDD. Em 2003, o percentual reduziu-se para 1,52\%, elevando-se, ligeiramente, para 1,59\% em 2005. Nos anos de 2008 e 2011 os valores foram de 1,84\% e 2,11\%, respectivamente. ${ }^{1}$ Apesar da evolução positiva a partir de 2003 , ao longo da década os níveis permaneceram inferiores ao inicial de 2000, os quais foram superados somente no último ano, em 2011.

O reduzido esforço de inovação empresarial é apontado como um obstáculo aos ganhos de produtividade e competitividade. Nesse sentido, o desafio de promover maior elevação dos gastos em PEDD por parte das empresas no Brasil incluiu-se na agenda das políticas industriais e de inovação, retomadas nos anos 2000 (BRASIL, 2010). ${ }^{2}$

Dentre essas políticas, criaram-se vários instrumentos de apoio público à $\mathrm{P} \mathcal{E} \mathrm{D}$, entre eles: incentivos fiscais, financiamentos e subvenções, bem como o incentivo à parcerias entre empresas inovadoras e instituições de pesquisa e tecnologia.

A literatura empírica tem utilizado técnicas econométricas para avaliar a eficácia desses instrumentos procurando responder à pergunta: os incentivos fiscais

1 Conforme dados da Pintec (IBGE, 2002, 2005, 2007, 2010 e 2013).

2 Em 2008, a Política de Desenvolvimento Produtivo (PDP) propunha como meta que o nível de gastos privados em PEBD em relação ao PIB deveria atingir 0,65\% em 2010,sendo que tal nível era de $0,51 \%$ em 2005 . 
e os financiamentos levam as empresas a aumentarem suas parcelas de receita direcionadas à PED?

A resposta implica mensurar se os efeitos desses instrumentos complementam, ou apenas substituem, os gastos privados em PEBD. No primeiro caso, os níveis de gastos privados aumentam, ocorrendo os chamados efeitos de adicionalidade, ou crowd in. Os recursos públicos complementaram os gastos privados.

No segundo caso, os recursos públicos apenas os substituem, ocorrendo efeito-substituição, ou crowd out. O montante realizado de gastos privados ocorreria de qualquer forma, independente da utilização dos instrumentos pelas empresas beneficiárias de programas de suporte.

As dúvidas em relação à eficácia desses instrumentos de políticas têm suscitado um conjunto amplo de investigações na literatura empírica sem que ainda haja consenso quanto aos resultados. Um dos aspectos que chama a atenção é a pouca ênfase dada a algumas características setoriais que, supostamente, condicionariam os efeitos das políticas (WENDT, 2014).

Dentre essas características, apontam-se as diferenças no grau de intensidade tecnológica de cada setor em que se localizam as empresas. Assim, é possível que o problema da eficácia tenha outra dimensão, já que os estímulos provocados por cada tipo de instrumento em setores distintos pelo grau de intensidade tecnológica podem variar.

Essa questão é fundamental para as políticas industriais e de inovação, já que o apoio público aos projetos de $\mathrm{P} \mathcal{E} \mathrm{D}$, nos setores considerados relevantes para o avanço tecnológico e competitivo da indústria, requer que as mesmas considerem a variação desses efeitos. Daí a necessidade de uma adequada combinação entre os instrumentos fiscais e financeiros que gere efeitos positivos sobre os gastos privados, dadas as diferenças setoriais.

Desse modo, o presente artigo situa-se no debate sobre avaliação de políticas de apoio à inovação e PEBD no Brasil, tendo como objetivo analisar os impactos dos incentivos fiscais e dos financiamentos sobre os gastos empresariais em PED, considerando o grau de intensidade tecnológica das empresas beneficiárias.

Essa análise será feita com dados concentrados na segunda metade dos anos 2000, baseados nas Pesquisas de Inovação Tecnológica (Pintec) de 2005, 2008 e 2011, de onde se buscam evidências de efeitos de adicionalidade, ou substituição, provocados pelos dois tipos de instrumentos. Sob tais aspectos, sua contribuição pode ser dividida nos pontos a seguir.

Em primeiro lugar, embora o foco de grande parte dos estudos seja a indústria de transformação, nota-se que a maioria desconsidera os diferentes graus de intensidade tecnológica dos setores em que se inserem as empresas. Uma vez que a relação entre gastos em PEBD e faturamento líquido diferem entre eles, uma hipótese plausível é que tais diferenças podem influenciar os efeitos esperados de cada 
instrumento específico. A baixa importância atribuída a esse aspecto está presente não somente na literatura internacional, como também nas análises para o Brasil.

Em segundo lugar, diferentemente da maioria dos estudos com base em microdados, que, em geral, realizam estimativas para apenas um período, foi possível acompanhar as mesmas empresas em dois períodos, com um painel para cada período consecutivo. Assim, a extensão das estimativas para dois painéis consecutivos incorporou momentos posteriores à implementação da Lei do Bem e de vários outros programas de financiamento público à $\mathrm{P} \mathcal{E} \mathrm{D}$, envolvendo parcerias ou não.

À maior ênfase das políticas de apoio à PẺ associou-se um maior número de empresas beneficiárias, sobretudo a partir de meados da década de 2000. Resta saber se ocorreram expansões significativas de gastos empresariais em PEBD. A possibilidade de aplicar estimativas, através do método de regressão diferenças em diferenças (DID), que mensuram a variação dos gastos de um período para outro, e não de seus níveis, representou um avanço, pois, em geral, são escassas as análises que acompanham as mesmas unidades ao longo do tempo.

Por fim, a realização das estimativas para cada instrumento de apoio em dois momentos subsequentes possibilitou também verificar se algum tipo de instrumento demonstra efeitos persistentes em algum grupo tecnológico específico.

Além desta introdução, o artigo divide-se em mais cinco partes: na segunda seção recupera-se,brevemente, o panorama das políticas industrais e dos programas mais recentes de apoio à inovação e PEBD;na terceira seção aborda-se a literatura sobre as políticas de suporte públicoà PẺ e as principais justificativas teóricas para o uso dos incentivos fiscais e do crédito subsidiado, apresentando-se algumas contribuições empíricas relevantes na literatura internacional e também estudos para o Brasil, mencionando-se os métodos para lidar com o problema do viés de seleção e obter estimativas precisas para captar os efeitos de crowd in e crowd out; Na quarta seção expõem-se os dados e o método de regressão DID com covariadas aplicado às bases da Pintec; na quinta seção são apresentados e discutidos os resultados do modelo; por fim, na sexta seção são traçadas as considerações finais.

\section{Breve Contexto das Políticas de Suporte à P\&D nos Anos 2000}

Nos anos 2000, com a retomada das políticas industriais e tecnológicas no Brasil, verificou-se um importante aumento de concessões de recursos voltados ao estímulo das atividades de inovação e PEDD. No contexto da Política Industrial, Tecnológica e de Comércio Exterior (Pitce) em 2003, reformulada em 2008 com a Política de Desenvolvimento Produtivo (PDP), esse aumento abrangeu várias modalidades de instrumentos. Como resultado, originaram-se vários programas de incentivo à inovação e PEBD, nos quais o governo visava atender à demanda 
das empresas reformulando e criando novos instrumentos como incentivos fiscais, financiamentos e subvenções.

Além de outras mudanças, ressalta-se que o marco legal de apoio à ciência e tecnologia (CËT) já contava com importantes alterações e a institucionalidade na qual operavam os processos de mobilização e alocação de recursos públicos também havia passado por reformulações. Em ambos os aspectos, legal e institucional, destacaram-se: a Lei do Bem (Lei ${ }^{\circ}{ }^{11.196 / 2005) ~(M C T I, ~ 2012), ~ a ~ p o s s i b i l i d a d e ~}$ de equalização das taxas de juros em operações de financiamentos reembolsáveis (Lei ${ }^{\circ}$ 10.332/2001) (BASTOS, 2003), a criação dos fundos setoriais desde fins dos anos 1990 e a Lei de Inovação (Lei no 10.973/2004)(CGEE/ANPEI, 2009). Assim, os novos instrumentos de apoio à PEBD e inovação emergem nesse contexto no qual se buscava fortalecer a agenda da inovação no país.

A Lei do Bem destacou-se por reorganizar a modalidade de incentivos fiscais, tendo em vista as experiências anteriores baseadas na antiga Lei de Incentivos Fiscais Lei $n^{\circ}$ 8.661/93 (ARAUJO, 2010). Esta, em apoio ao Plano de Desenvolvimento Tecnológico da Industria (PDTI) e ao Plano de Desenvolvimento Tecnológico da Agropecuária (PDTA), teve como objetivo estimular o interesse por parte das empresas em realizar maiores investimentos voltados à geração e difusão tecnológica. No entanto, as avaliações disponíveis mostram que o alcance desses instrumentos, no âmbito dos programas mencionados, foi limitado (MATESCO; TAFNER, 1996).

Ainda pertecente à modalidade incentivos fiscais, o conjunto de instrumentos de suporte à PEBD incorporou a já existente Lei de Informática, que, por motivos diversos, foge do escopo de análise deste artigo. Tal instrumento foi criado nos anos 1990 e tinha como finalidade estimular o complexo eletrônico do país através de maiores investimentos em PEBD. Através da redução do IPI, como benefício para os bens incentivados, o investimento em PEBD é um requisito de contrapartida a ser cumprido pelas empresas, que, além disso, devem atender ao chamado Processo Produtivo Básico (PPB). ${ }^{3}$

No que diz respeito aos instrumentos financeiros de apoio à P\&BD, observou-se maior ênfase por parte das políticas governamentais durante a segunda metade dos anos 2000. Cabe ressaltar que, historicamente, a Financiadora de Estudos e Projetos (Finep) representa a principal agência de fomento à inovação no Brasil. No entanto, até os anos 1990, o alcance das operações de financiamento à P\&BD restringiu-se a um número bem limitado de empresas. A razão suposta para tal performance era a ausência de garantias reais adequadas por parte das empresas demandantes, fato que deriva da própria natureza da atividade de P\&D, que envolve riscos e custos mais elevados que as atividades tradicionais.

3 O PPB define-se como um conjunto mínimo de operações que deve sem ser realizadas no interior da empresa como uma forma de estimular a produção industrial interna. 
O mecanismo de equalização das taxas de juros teria sido uma das alternativas criadas para superar tal limitação. A menor restrição orçamentária, derivada da melhora do quadro macroeconomico da época, viabilizou os esforços para o uso desse mecanismo, que já integrava o orçamento do Fundo Nacional de Desenvolvimento Científico e Tecnológico (FNDCT). Porém, conforme apontam Pacheco e Corder (2010), embora visasse reduzir os problemas da ausência/insuficiência de garantias reais, sua difusão a um maior número de empresas ocorre somente a partir de 2007 no âmbito do programa Pró-Inovação, da Finep.

Outra importante mudança nas fontes de financiamento à inovação foi representada pelos fundos setoriais, em 1997. Na concepção original, sua forma de gestão buscava reduzir a dependência de recursos às variações orçamentárias, garantindo, assim, maior estabilidade diante da ocorrência de crises fiscais.

Procurava-se, sobretudo, garantir os recursos financeiros à inovação, fomentar parcerias entre as universidades, as instituições de pesquisa e o setor produtivo, além de assegurar a continuidade dos investimentos em P\&D nos setores privatizados ou abertos aos investimentos privados na década de $1990 .{ }^{4}$

No que tange à Lei de Inovação, a partir de 2004 definiram-se as bases legais para parcerias entre universidades, instituições de CËT sem fins lucrativos e empresas. ${ }^{5}$ Talvez a medida mais notória tenha sido a criação da subvenção econômica direta às empresas, modalidade não reembolsável, operacionalizada através da Finep, que, ao somar-se aos outros instrumentos, contribuiria para diversificar o menu de instrumentos de apoio à PEBD .

A compreensão mais adequada acerca do quadro de intensificação do suporte público à PËD implica considerar, além das mudanças mencionadas, o momento de retomada do crescimento econômico a partir de 2004. Tal contexto favoreceu a aplicação tanto dos incentivos fiscais, quanto dos financiamentos, através da elevação do montante de recursos públicos disponíveis que iriam apoiar as estratégias de políticas industriais e de inovação.

Do ponto de vista dos formuladores de políticas, esperava-se alterar de forma favorável o quadro das decisões de investimento em inovação e, assim, em PẺD, pois o papel dos incentivos fiscais e dos financiamentos, enquanto atenuantes dos custos e riscos envolvidos nas etapas críticas daquelas atividades, seria reforçado pelo ambiente de menor incerteza quanto ao retorno dos investimentos e melhoria das receitas.

4 As receitas provêm de várias fontes, sendo que as mais importantes são: parcela dos royalties do petróleo, contribuição das empresas sobre resultados da exploração de recursos naturais pertencentes à União, Contribuição de Intervenção no Domínio Econômico (Cide) sobre remessas ao exterior para pagamentos referentes à transferências de tecnologia e outros. de infraestrutura de pesquisa de instituições científicas e tecnológicas (ICTs). Ver CGEE/ANPEI (2009). 
Segundo Araújo (2010), a reorganização promovida pela Lei do Bem simplificou o uso dos incentivos fiscais. Tal aspecto, junto ao quadro mais favorável de crescimento econômico, permitiu aumentar a renúncia fiscal pelo governo, sobretudo a partir de 2007. Assim, ao garantir que os valores dedutíveis pudessem ultrapassar os gastos em PEBD, ampliou-se o acesso a um maior número de empresas.

A retomada do crescimento também permitiu a redução paulatina dos contingenciamentos do Ministério da Ciência e Tecnologia (MCT), ampliando-se os recursos orçamentários da Finep, o que contribuiu para o aumento dos recursos direcionados aos fundos setoriais e, em particular, das fontes de financiamento não reembolsáveis (CORDER, 2008; PACHECO; CORDER, 2010). Além disso, o Banco Nacional de Desenvolvimento Econômico e Social (BNDES) passou a incorporar a inovação entre suas prioridades, principalmente pela necessidade de apoiar os projetos da Pitce.

No caso da Finep, a partir de 2004 lançou-se o programa Pró-Inovação, que visava estimular projetos com valor mínimo de $\mathrm{R} \$ 1$ milhão, voltado a empresas de médio e grande porte, em substituição ao anterior programa Apoio ao Desenvolvimento Tecnológico da Empresa Nacional(Adten). A intenção explícita era também a de fomentar projetos consistentes com as diretrizes da Pitce.

Além disso, para contemplar empresas de menor porte e amenizar problemas enfrentados de racionamento de crédito lançou-se o programa Juro Zero em $2004 .^{6}$

Em 2008, o programa Pró-Inovação foi substituído pelo Inova Brasil, voltado às médias e grandes empresas, com exigências de garantias, concentrando a carteira do programa em um número reduzido de setores intensivos em PED. Com isso, atrelavam-se as linhas de financiamento aos objetivos da PDP de 2008 (CGEE/ ANPEI, 2009).

No que diz respeito à atuação do BNDES no suporte à inovação, destacam-se no período a criação de duas linhas de financiamento: o Programa Desenvolvimento e Inovação (PDI) e o Programa Inovação Produção (IP), em 2006, sendo que a ênfase nos esforços em PEBD restringiu-se ao primeiro. Visando alterar e ampliar a forma de apoio à inovação pelo banco, esses programas foram substituídos pelas linhas Inovação Tecnológica e Capital Inovador (TAVARES, 2012).

Em 2010, diante dos efeitos da crise internacional, lançou-se o Programa de Sustentação do Investimento (PSI), que contou com a ação conjunta entre Finep e BNDES.7 Em 2011, último ano dos dados examinados neste trabalho, o BNDES

6 No programa Juro Zero, dispensava-se a apresentação de garantias reais e não havia incidência de juros levando a uma maior participação das pequenas e microempresas.

7 No âmbito do PSI, a ação conjunta implicou o repasse de recursos do BNDES para a Finep e as taxas do programa Inova Brasil, da Finep, atrelaram-se às taxas das linhas Inovação Tecnológica e Capital Inovador do BNDES. Além dos recursos do BNDES, houve também recursos do Tesouro. 
extinguiu as linhas existentes de apoio à inovação, substituindo-as por uma única linha, a BNDES Inovação. ${ }^{8}$

No âmbito dos programas de apoio à PEBD com base nos recursos não reembolsáveis, ${ }^{9}$ destacaram-se a partir de 2005: o Programa de Apoio à Pesquisa em Empresas (Pappe) - com repasses de recursos da subvenção -, as chamadas públicas de projetos de inovação de produtos e processos de micro e pequenas empresas, em cooperação com as instituições científicas e tecnológicas (ICTs) envolvendo o MCT, o Serviço de Apoio às Micro e Pequenas Empresas (Sebrae) e a Finep-e também o Fundo Tecnológico (Funtec) do BNDES.

Este último é um mecanismo de subvenção, reestabelecido a partir de 2004, voltado à pesquisa, desenvolvimento e inovação (PDEI) de projetos que envolvam relevantes desafios tecnológicos, grau de ineditismo e possibilidade de aplicação da tecnologia em outros setores.

Por fim, é preciso ressaltar algumas diferenças institucionais entre o BNDES e a Finep relacionadas diretamente à mobilização e alocação de recursos e que podem limitar a eficácia dos financiamentos.

No caso do BNDES, sabe-se que o Fundo de Amparo ao Trabalhador (FAT) representa sua principal fonte de recursos, dando-lhe certa estabilidade em sua estrutura de funding, com garantia constitucional e repasses obrigatórios, além de autonomia em termos alocativos (TAVARES, 2012). Já os recursos da Finep dependem do FNDCT, que possui legislações próprias e que acaba interferindo e subordinando a agência às regras para aplicação de recursos.

Nesse sentido, a tarefa de sustentação e expansão dos financiamentos fica comprometida, pois obrigatoriamente a agência depende de negociações anuais para a captação de recursos externos. Tal fragilidade é realçada dado o baixo patrimônio líquido da Finep (CGEE/ANPEI, 2009).

Assim, o reforço da presença das duas agências oficiais redundaria na expansão de fontes alternativas de recursos, além dos incentivos fiscais, incrementando o mix disponível de suporte público à inovação.

\footnotetext{
8 Os programas mencionados do BNDES junto ao Pró-Inovação, Inova Brasil e Juro Zero incluem-se na Pintec como financiamentos sem parcerias.

9 Tais programas incluem-se na Pintec como financiamentos em parcerias.
} 


\section{A Eficácia dos Incentivos Fiscais e dos Financiamentos à P\&D: Alguns Aspectos da Literatura Internacional e o Debate Recente no Brasil}

O debate teórico sobre o problema dos baixos níveis de investimentos em PEBD atribui às falhas de mercado as razões que justificam o uso de intervenção de políticas (ARROW, 1962; NELSON, 1959). A apropriação plena dos retornos da PEBD encontra-se entre as causas daquelas falhas, além das imperfeições no mercado de capitais como assimetrias de informações e risco moral, conforme leituras mais recentes (HALL; LERNER, 2010) .

$\mathrm{O}$ argumento principal para o uso das políticas é que tais falhas resultam em níveis de investimentos abaixo do ótimo (underinvestment) e, dentre os instrumentos disponíveis, destacam-se o crédito subsidiado ou os incentivos fiscais. Através desses, espera-se a geração de efeitos positivos e indutores do investimento privado a fim de preencher o gap e se chegar ao nível ideal.

Entretanto, é possível que o estímulo governamental decorra não apenas da necessidade de corrigir o desequilíbrio entre retornos privados e retornos sociais em determinados setores ou empresas. Assim, cabe esclarecer que também seria possível aos governos estimularem a PEB porque a entendem como um importante determinante do crescimento futuro da economia. Embora a correção das falhas de mercado, na busca pela elevação dos gastos em PEBD e inovação, influencie o crescimento econômico, há diferenças entre as duas intenções (CARVALHO, 2011).

As intenções de crescimento influenciam as políticas de apoio à PEBD, e a realização de projetos não necessariamente atende programas específicos de interesse governamental, que, em geral, direcionam-se a determinados setores ou empresas. Essa é uma situação típica em que os incentivos fiscais seriam o instrumento mais adequado porque, com eles, a alocação dos recursos não ocorre através da interferência do governo na escolha dos projetos. Logo, há maior autonomia de escolha por parte das empresas, predominando critérios de decisões alocativas de mercado, em vez de intenções alocativas de políticas (MONTMARTIN; HERRERA, 2014).

Dessa forma, a diferença relevante em relação ao crédito subsidiado é que este permite ao governo maior controle sobre a natureza da PEBD realizados pelo setor privado. São os casos de projetos de interesse governamental com objetivos nas áreas de defesa, saúde e energia, por exemplo, já que nelas são reconhecidos os gaps significativos entre retornos privados e retornos sociais (OECD, 2002).

No primeiro caso, dos incentivos fiscais, tanto pela menor discricionariedade de empresas ou setores, quanto pela maior autonomia na escolha dos projetos, há um risco maior envolvendo o apoio público, pois é mais provável que os recursos direcionem-se aos projetos já existentes nos portfólios de PEBD das empresas que, 
de uma forma ou de outra, seriam realizados; ou, então, uma maior probabilidade de ineficiência na aplicação dos recursos públicos, já que as empresas ou setores beneficiados não demonstrariam sinais de subinvestimento.

Outro ponto importante, e que tende a restringir o acesso das empresas de maior porte aos recursos públicos, é que os incentivos fiscais são concedidos somente após a empresa ter realizado e desembolsado recursos em um determinado projeto. O contrário ocorre com os financiamentos, que poderão ser concedidos antes da realização.

Não há consenso na literatura quanto à melhor performance de um instrumento em relação a outro. Porém, a implicação que surge de uma estrutura de incentivos apoiada em demasia nos incentivos fiscais seria limitar os projetos somente naqueles em que os retornos privados fossem mais atrativos (POTTELSBERGHE; ALLI, 2003).

Já em relação aos financiamentos, um argumento contrário são os elevados custos administrativos envolvidos, apesar da defesa favorável de que o maior grau de intervenção por parte das políticas permite discriminar projetos com elevado potencial de spillovers e retornos sociais mais elevados. No entanto, do ponto de vista dos formuladores de políticas, tal fato não elimina o problema de assimetria em relação às informações dos projetos, o que acaba acentuando o risco de insucesso das políticas.

Nesse ponto, David, Hall e Toole (2000)lembram da existência de falhas do governo em face da tendência das escolhas serem influenciadas por grupos de pressão ou, então, da necessidade de se demonstrar sucesso de políticas, que nem sempre corresponde às escolhas ótimas em termos de projetos.

Um fato reconhecido na literatura é que o uso dos instrumentos de apoio à PDEI por parte das empresas não ocorre através de escolhas aleatórias por parte das agências governamentais, mas sim com base nas características das empresas, ou preferências dos indivíduos, com influências nos gastos em PEBD (CZARNITZKI; ALMUS, 2002; CZARNITZKI; KRAFT, 2004). Isso torna os resultados das avaliações de impacto fortemente sujeitos a refletir tanto o efeito do tratamento, quanto o efeito da atribuição não aleatória, originando viés de seleção nas estimativas.

Por outro lado, as empresas que exibem níveis mais elevados de gastos em PEBD terão maior probabilidade de sucesso em projetos públicos subsidiados, o que leva à autosseleção (LACH, 2002). Assim, a origem do viés relaciona-se tanto a fatores observáveis quanto a não observáveis.

De forma predominante, os gastos privados em PEBD são tratados na literatura como esforços de inovação (inputs) (ASCHHOFF, 2009). Ao mensurá-los, emprega-se o conceito de adicionalidade, que procura avaliar em que medida os instrumentos de suporte público presentes nas políticas estimulam novas atividades de PED, ou níveis mais elevados de gastos privados (input additionality). 
Os casos de elevações positivas e significativas de gastos privados são conhecidos como efeitos de crowd in, revelando-se o papel positivo dos instrumentos, já que, se ausentes, o acréscimo de gastos não seria observado (BUISSERET; CAMERON; GEORGHIOU, 1995). Por outro lado, casos opostos em que os gastos privados são apenas substituídos pelos gastos públicos dão origem aos chamados efeitos de substituição, ou crowd out, caracterizando um risco ao qual as políticas de apoio estão expostas. O argumento teórico é que as empresas apoiadas teriam incentivos para reduzir o custo de PEBD e substituir seus gastos próprios pelos fundos públicos, implicando saber o quanto tal empresa teria gasto caso não tivesse recebido o apoio.

Apesar de evidências do efeito adicionalidade em alguns países, após cinco décadas de investigação não se encontram respostas conclusivas na literatura (DAVID; HALL; TOOLE, 2000).

Lach (2002), por meio de dados em painel de empresas israelenses entre 1990 e 1995, realiza estimativas de DID e encontra efeitos positivos, mas não significativos, dos subsídios sobre PËD. Estimativas em painel dinâmico, com o intuito de captar efeitos a longo prazo dos subsídios sobre os gastos em PEBD, revelaram que, embora positivos, os efeitos ficam abaixo dos resultados esperados pelas políticas (dollarbydollar).

Czarnitzki e Hussinger (2004) empregam técnicas de propensity matching score para empresas e encontram que os efeitos sobre a intensidade de PED das empresas tratadas são superiores em relação às não tratadas, rejeitando, assim, a hipótese de crowd out. Eles concluem que as empresas elevam a inversão de seus recursos próprios quando recebem o suporte público.

Marino et al. (2016) utilizam dados para uma amostra de empresas francesas entre 1993 e 2009 combinando os métodos de DID com propensityscore. Diferentemente da maioria das abordagens anteriores, este estudo simula testes com diferentes dosagens de tratamento a fim de encontrar se há uma quantidade ótima de incentivos que leve à adicionalidade. Não houve efeitos significativos, nem de adicionalidade, nem de substituição, havendo indícios de que, para níveis médios de dosagens, os incentivos fiscais parecem gerar efeitos de crowd out.

Em uma análise recente de metarregressão, Dimos e Pugh (2016) selecionaram um amplo conjunto de publicações heterogêneas e controladas por viés de seleção, e, embora tenham rejeitado a hipótese de crowd out, não encontraram efeitos significativos de adicionalidade. Os autores destacaram que o tratamento de heterogeneidades não observáveis nas firmas explicam os efeitos heterogêneos encontrados na literatura.

Quando considerados por setores industriais, os gastos em PED, bem como o grau de importância para inovar atribuído pelas empresas não são homogêneos. Fatores como oportunidades tecnológicas diferem entre os setores e influenciam 
não somente os níveis de PËD, como também outros esforços inovativos (COHEN, 2010).

Isso tem levado alguns autores à suposição de que empresas de setores mais intensivos em tecnologia, por apresentarem níveis de produtividade mais elevados em relação aos de menor intensidade, deveriam ser o foco principal das políticas de apoio à $\mathrm{P} \mathcal{}$ D e inovação. O aumento da $\mathrm{P} \mathcal{}$ D naqueles setores seria de primordial importância para o crescimento econômico, dado o seu alto potencial de criação e difusão de inovações sobre outros setores da indústria (CRESPI; QUATRARO, 2013). No entanto, embora o papel desempenhado pelos setores mais intensivos para o crescimento econômico seja reconhecido por vários autores, nada assegura que o apoio público às empresas neles localizadas produzirá efeitos superiores quando comparados aos setores de menor intensidade.

Callejón e García-Quevedo (2005), por exemplo, ao tratarem de empresas espanholas argumentam que não necessariamente existe correspondência entre esforço privado e suporte público, sugerindo que tal característica não seria restrita somente àquele país. Os autores mostram, inclusive, que alguns setores de baixa intensidade tecnológica e com pouca contribuição ao crescimento são os mais favorecidos pelos subsídios públicos. A análise baseou-se em painel de efeitos fixos contornando características setoriais específicas que influenciam o nível de gastos em P\&D. Entre elas: apropriabilidade, concentração e oportunidades tecnológicas. Os resultados obtidos permitiram verificar efeitos de complementariedade nos setores de média-alta e média-baixa tecnologia, sendo que, para o setor de alta tecnologia, não houve efeitos significativos.

Castellacci e Lie (2013) realizam uma análise de metarregressão e encontram efeitos diferenciados do apoio público quando considerados em nível setorial. No entanto, a análise limitou-se apenas aos efeitos dos incentivos fiscais. Nas publicações levantadas pelos autores, houve efeitos de adicionalidade em empresas nos setores de baixa tecnologia. Um dos argumentos plausíveis, nesses casos, é que os níveis iniciais de gastos em PEBD são inferiores àqueles dos setores mais intensivos, de tal forma que um pequeno aumento de gastos em resposta aos incentivos fiscais representa um efeito de adicionalidade relativamente de maior magnitude.

No Brasil, a literatura sobre impactos das políticas de incentivo à inovação é recente, bem como os próprios dados sobre empresas inovadoras. As publicações iniciais começaram a partir de 2000, com a primeira edição da Pintec. Apesar disso, tem havido preocupação em se produzir análises baseadas no comportamento inovador da indústria nacional, que, semelhante ao presente estudo, utiliza os microdados da Pintec e adota metodologias similares às referências internacionais.

Nesses estudos incluem-se aqueles que procuraram avaliar o impacto de incentivos fiscais ou de mecanismos financeiros para alavancar os gastos privados em atividades inovativas em geral, ou somente em PEBD. No entanto, até por conta 
de seu caráter recente, alguns deles têm se concentrado na análise de períodos curtos, muitas vezes com amostras restritas apenas a um ano.

Avellar (2007), com base na Pintec de 2003, avaliou três programas governamentais: incentivos fiscais, financiamento não reembolsável e financiamento reembolsável. A análise foi feita após a realização de um procedimento de matching para pareamento entre empresas beneficiárias e não beneficiárias. Os resultados mostraram que a participação nos programas torna a empresa mais inovadora com diferenças de médias significativas em algumas variáveis, como gastos em atividades inovativas em relação à receita líquida (GAI/RLV) e gastos em PEB em relação à receita líquida (GPD/RLV), rejeitando a hipótese de crowd out.

Em um estudo mais recente, aplicou-se o mesmo método para os programas apoiados por financiamentos, incentivos fiscais, compra de máquinas e equipamentos, concessão de bolsas e capital de risco. Com base nos microdados da Pintec de 2010, restringiu-se a amostra às pequenas empresas, que, comparadas às empresas não apoiadas, revelaram aumento de $125 \%$ dos gastos em atividades inovativas (AVELLAR; BOTELHO, 2015)destacando-se a proliferação de programas direcionados às empresas de pequeno porte. O objetivo do presente artigo é o de analisar a abrangência e efetividade dos atuais programas de apoio à inovação direcionados às pequenas empresas brasileiras. Elabora-se uma análise evolutiva da incidência dos programas sobre seu público alvo nos anos 2000, e da sua efetividade, por meio de indicadores de esforço e desempenho inovativos das empresas contempladas e não contempladas pelos programas, considerando-se também o recorte setorial. A análise empírica baseou-se em dados das últimas três edições da Pesquisa de Inovação Tecnológica (Pintec.

Araújo et al. (2012) avaliam os impactos do fundos setoriais sobre as empresas que os acessaram entre 2001 e 2006. Através de dados em painel de empresas e estimativas das taxas de crescimento dos gastos em pessoal ocupado nas atividades de PEBD, concluíram que as taxas são significativamente superiores para as empresas que os acessaram.

Analisando os efeitos do Programa Adten para o ano de 2000, De Negri, De Negri e Lemos (2008) adotaram tanto o procedimento de matching, quanto um modelo de seleção em dois estágios, de Heckman (1979), e encontraram efeitos positivos e significativos sobre os gastos em PEDD.

$\mathrm{Na}$ literatura mencionada, poucos trabalhos realizaram estimativas por tipos diferentes de instrumentos e considerando o grau de intensidade tecnológica. Uma exceção é o trabalho de Kannebley Júnior e Porto (2012), que analisa duas modalidades distintas de incentivos fiscais: Lei de Informática, com dados de 2001 a 2008, e Lei do Bem, de 2006 a 2010. As estimativas foram realizadas em mínimos quadrados agrupados (OLSpooled), mínimos quadrados ordinários (MQO) e Tobit com efeitos fixos. Evidências de adicionalidade ocorreram somente para a Lei do 
Bem, resultando que as empresas elevam seus dispêndios em PEDD interna, em média de 7 a 11\%, com impactos mais fortes para os setores de média-baixa e baixa intensidade tecnológica.

Outro caso é o de Shimada (2014), que analisa os impactos da Lei do Bem sobre os gastos em PED das empresas de 2005 a 2008 por técnicas de matching e modelos empíricos em painel. Houve evidências de que as empresas dos setores de média-baixa tecnologia, seguidas pelas de baixa e média-alta tecnologia, apresentaram adicionalidade de PED. À exceção dos setores de alta tecnologia, rejeitou-se, portanto, para aqueles grupos, a hipótese de crowd out.

Um dos argumentos que justifica a importância de entender os efeitos dos instrumentos considerando os diferentes graus de intensidade tecnológica encontra-se na própria natureza da PED, que, ao envolver maior complexidade em setores mais intensivos, requer níveis mais elevados de gastos privados. Para as políticas, tal fato talvez implique graus de reduções de riscos e custos dos projetos nem sempre alcançáveis pelos montantes propiciados pelos recursos públicos.

Além disso, as oportunidades tecnológicas presentes para as empresas dos setores mais intensivos estão em constante mudança, envolvendo maiores desafios tecnológicos, riscos e, portanto, elevadas necessidades de recursos para PED. Tais circunstâncias levam a crer que o volume necessário de recursos públicos para que tais empresas se disponham a aumentar seus recursos próprios para a realização de projetos de PËD mais desafiadores tende a ser muito elevado.

Épossível, então, que os efeitos de cada tipo de instrumento diferenciem-se conforme os setores em que são aplicados, assim como o aumento dos gastos de forma permanente nos setores mais intensivos dependa do aumento também permanente dos recursos (COCCIA, 2012). Isso implica um desafio à capacidade de mobilização, sustentação e alocação de recursos por parte das agencias oficiais.

Para os setores mais intensivos, o papel das políticas, no que diz respeito às mudanças de percepção das empresas quanto aos riscos, talvez envolva maior dificuldade em relação aos de menor intensidade, já que nestes últimos as oportunidades tecnológicas são mais escassas, além de estarem menos sujeitas à rápidas mudanças tecnológicas. $\mathrm{O}$ alívio nas restrições financeiras para as suas empresas seria obtido mais facilmente e o papel dos instrumentos poderia ser mais efetivo nesse caso.

Do ponto de vista de algumas características das firmas, as diferenças entre os setores de menor e maior intensidade tecnológica implicam também competências tecnológicas mais elevadas nos últimos (LEE, 2011). Isso leva a supor efeitos diferenciados do suporte público, já que o desenvolvimento e execução de projetos de PEBD mais arrojados não necessariamente implicaria aumentos tão significativos de esforços tecnológicos, pois as habilidades prévias presentes nessas empresas são mais elevadas. 
Falta ênfase da literatura internacional nas relações entre o grau de intensidade tecnológica do setor no qual se insere a empresa e os efeitos dos instrumentos. Conforme já exposto, essa lacuna chama a atenção para uma possível existência de efeitos diferenciados de cada tipo de instrumento, tornando-se uma questão relevante para o desenho e a elaboração das políticas. No Brasil, as poucas análises limitaram-se aos incentivos fiscais, com destaque para os últimos trabalhos citados. Uma possível explicação para isso é que os montantes da renúncia fiscal são muito superiores às operações de financiamento, favorecendo a disseminação dos incentivos fiscais, porém, entre empresas de maior parte, conforme mencionado por Pacheco (2011).

A falta de respostas conclusivas quanto à maior eficácia de um determinado instrumento, ou mesmo quanto à possibilidade de um mix mais eficaz sugere a necessidade de se testar de forma individual cada tipo de instrumento em amostras por diferentes graus de intensidade tecnológica.

\section{Dados e Método}

Os dados utilizados nas estimativas foram extraídos das bases de microdados da Pintec, do IBGE, referentes aos períodos: 2003-2005 (IBGE, 2007), 2006-2008 (IBGE, 2010) e 2009-2011 (IBGE, 2013). Através dessas três bases, foram criados dois painéis de empresas com períodos consecutivos: um incorporando os dados tanto das publicações de 2005 e 2008 e outro com dados de 2008 e 2011. Para cada painel foram acompanhadas as mesmas empresas.

\subsection{Critério de seleção e tratamento dos dados}

O critério de seleção baseou-se na Classificação Nacional das Atividades Econômicas, nível de desagregação 3 (CNAE-3). Posteriormente, agruparam-se por grau de intensidade tecnológica, segundo a classificação da Organização para a Cooperação e Desenvolvimento Econômico (OCDE): alta tecnologia; média-alta, média-baixa e baixa tecnologia.

Conforme mencionado anteriormente, o método DID possibilita avaliar se houve efeitos de adicionalidade (crowd in) ou de substituição (crowd out) advindos do uso de mecanismos de suporte público à PEBD, comparando-se empresas beneficiárias (grupo de tratamento) com as não beneficiárias (grupo de controle). Para o grupos de tratamento (GT), foram selecionadas as empresas apoiadas por cada tipo específico de instrumento no período “", mas que não receberam em " e nem nos períodos anteriores. Para o grupo de controle (GC), foram selecionadas as empresas que não se beneficiaram em nenhum dos momentos. 
As estimativas consistiram em comparar a diferença de crescimento dos gastos realizados em PEBD entre as empresas que foram beneficiárias no período corrente e as que não foram no período anterior (GT) com as que não foram em nenhum dos dois períodos (GC). A aplicação desse procedimento em amostras de empresas divididas por classes tecnológicas permitiu avaliar se a variação dos gastos em PẺD foi significativa, ou não, conforme o uso de cada tipo de instrumento.

O cálculo do estimador envolve dois procedimentos. No primeiro, calcula-se a diferença na média entre os gastos de PEBD de cada grupo antes do uso de determinado instrumento e essa mesma diferença depois que houve o tratamento. No segundo, tira-se a primeira diferença dos resultados ao longo do tempo. ${ }^{10}$

Conforme lembra Meyer (1995), os dois grupos devem ser passíveis de comparação ao longo do tempo. Equivale a dizer que o grupo que não recebe o tratamento, presumivelmente, estaria sujeito às mesmas influências daquele que recebeu. Nessas condições, conforme será visto, o modelo deve considerar um termo que capture as influências temporais comuns aos dois grupos.

Além disso, a maior similaridade entre os grupos de comparação é outro fator que favorece a aplicação do método. Nesse sentido, além das amostras segmentadas por grupos tecnológicos, as empresas selecionadas foram apenas aquelas cujos gastos em PEBD foram positivos nos períodos anteriores e posteriores ao uso de cada instrumento.

Trata-se de uma técnica de avaliação de impacto aplicável nos casos em que os dados são provenientes de um experimento natural (ou quase-experimento) em que os grupos de tratamento e de controle surgem de mudanças específicas (alterações exógenas) da política governamental. Portanto, não resultam de escolhas aleatórias (WOOLDRIDGE, 2011).

O método permite contornar o problema da endogeneidade controlando características não observáveis e invariantes no tempo, além de permitir a inclusão de covariadas para controlar o viés de observáveis. Apesar de suas limitações, tais procedimentos amenizam o problema de comparações entre unidades heterogêneas.

Assim, tanto para o crédito subsidiado, quanto para os incentivos fiscais, a falta de aleatoriedade implica que sua distribuição para as empresas beneficiárias, através das agências públicas, leve em consideração algumas características específicas à determinadas empresas. Por sua vez, estas influenciam diretamente nos gastos em PED. Por outro lado, as empresas que exibem níveis mais elevados de gastos em PEBD terão maior probabilidade de sucesso em projetos públicos subsidiados, gerando autosseleção (LACH, 2002).

Desse modo, a origem do viés relaciona-se tanto a fatores observáveis quanto a não observáveis. A aplicação do método DID possibilita amenizar o viés causado pelos não observáveis desde que seja possível aplicar à base de dados uma estrutu-

10 Considerando-se que cada estimativa trabalha com dois períodos: 2005 e 2008; 2008 e 2011. 
ra de painel de efeitos fixos em dois períodos, ao mesmo tempo que a inclusão de variáveis de controle, por sua vez, ameniza o viés advindo dos fatores observáveis.

Entretanto, outras fontes bem pouco exploradas pela literatura podem dar origem a estimativas enviesadas, segundo advertem Duflo, Bertrand e Mullaninathan (2002). Para os autores, as estimativas DID via MQO estão sujeitas a problemas de correlação serial entre os erros que podem enviesar os estimador de impacto DID.

\subsection{Variáveis Utilizadas e o Modelo Empírico}

As seguintes variáveis foram especificadas para o modelo apresentado em seguida:

Tabela 1 - Descrição das variáveis

\begin{tabular}{|c|c|c|}
\hline $\begin{array}{l}\text { Abrevia- } \\
\text { ção }\end{array}$ & Variáveis & Descrição \\
\hline $\ln P D_{i}$ & $\begin{array}{l}\text { Variável dependente } \\
\text { do modelo. Log da } \\
\text { intensidade de PEBD. }\end{array}$ & $\begin{array}{l}\text { Log natural das somas dos gastos em P\&D interna } \\
\text { e externa em relação à receita líquida de vendas. }\end{array}$ \\
\hline$T_{i}$ & $\begin{array}{l}\text { Variável que indica se } \\
\text { a empresa pertence } \\
\text { ou não ao grupo de } \\
\text { tratamento. }\end{array}$ & $\begin{array}{l}\text { Igual a um para as observações pertencentes ao } \\
\text { grupo de tratamento, indicando que, no caso, a } \\
\text { empresa } i \text { recebeu o tratamento; igual a zero para } \\
\text { aquelas pertencentes ao grupo de controle. }\end{array}$ \\
\hline$D_{2}$ & Dummytemporal. & $\begin{array}{l}\text { Igual a um para os dados referentes ao segundo } \\
\text { período; igual a zero para o primeiro período. }\end{array}$ \\
\hline$T_{i} D_{2}$ & & $\begin{array}{l}\text { Variável de interação entre a dummy temporal, , } \\
\text { e a dummy de participação em algum programa } \\
\text { governamental específico, seja incentivos fiscais, } \\
\text { financiamentos (parcerias e sem parcerias). }\end{array}$ \\
\hline \multirow[t]{2}{*}{$\varepsilon_{i}$} & $\begin{array}{l}\text { Erro aleatório não } \\
\text { observado }\end{array}$ & (Variáveis independentes não incluídas). \\
\hline & $\begin{array}{l}\text { Variáveis de controle } \\
\left(X_{i}\right)\end{array}$ & \\
\hline LnPoPD & $\begin{array}{l}\text { log natural da mão de } \\
\text { obra mais qualificada } \\
\text { em PEDD em dedica- } \\
\text { ção exclusiva. } \\
\end{array}$ & $\begin{array}{l}\text { Log do número de pesquisadores com nível su- } \\
\text { perior (doutores, mestres e graduados) ocupados } \\
\text { nas atividades de PGD em dedicação exclusiva em } \\
\text { relação à mão de obra total. }\end{array}$ \\
\hline Po & Pessoal ocupado. & $\begin{array}{l}\text { Variável de tamanho da empresa. Mede o total da } \\
\text { mão de obra empregada. }\end{array}$ \\
\hline$P o^{2}$ & $\begin{array}{l}\text { Pessoal ocupado ao } \\
\text { quadrado. }\end{array}$ & Termo quadrático da mão de obra empregada. \\
\hline LnVBP & $\begin{array}{l}\text { log natural do valor } \\
\text { bruto da produção. }\end{array}$ & $\begin{array}{l}\text { Log do valor bruto da produção corrente da em- } \\
\text { presa; proxy da demanda esperada ou vendas. }\end{array}$ \\
\hline
\end{tabular}

Fonte: Elaboração própria. 
Cada empresa da amostra foi observada em dois períodos de tempo para cada estimativa nos anos: 2005 e 2008; 2008 e 2011 . Assim, o modelo assume a seguinte especificação:

$$
\ln P D_{i}=\beta_{0}+\delta_{0} D_{2}+\beta_{1} T_{\mathrm{i}}+\beta_{2} X_{\mathrm{i}}+\delta_{1} T_{\mathrm{i}} D_{2}+\varepsilon_{i}
$$

em que $i$ corresponde às empresas; $\beta_{0}$ : é o valor esperado da variável estudada para o grupo de controle antes da implementação da política - é o intercepto da equação; $\delta_{0}$ : mede o impacto do segundo período, após a mudança, sobre a variável estudada,representando a tendência temporal comum aos dois grupos; ${ }^{11} \beta_{1}$ : mede o impacto do grupo de tratamento sobre a variável estudada de forma permanente,ou seja, é o impacto causado pela diferença entre os dois grupos que não se explica pela ocorrência do evento exógeno (no caso deste estudo, a mudança de políticas) - trata-se da diferença permanente entre eles; $\beta_{2}$ : mede o impacto das variáveis de controle de características observáveis das empresas antes da implementação do programa governamental; $\delta_{1}$ : representa o parâmetro de interesse da regressão e mede a diferença do grupo de tratamento em relação ao grupo de controle após a ocorrência do evento (mudança de política)-é o efeito médio do tratamento, portanto, representa o estimador de diferenças em diferenças.

Esse coeficiente de interesse (estimador) pode ser expresso da seguinte forma:

$$
\hat{\delta}_{1}=\left(\overline{\mathrm{y}}_{p, t}-\overline{\mathrm{y}}_{a, t}\right)-\left(\overline{\mathrm{y}}_{p, c}-\overline{\mathrm{y}}_{a, c}\right)
$$

no qual $c$ significa controle, $t$, tratamento, $a$, antes e $p$, pós (depois).

O estimador de diferenças em diferenças será não viesado desde que:

a) o modelo esteja corretamente especificado, requerendo a inclusão de outras variáveis de controle;

b) o termo de erro tenha média igual a zero, $E\left[\varepsilon_{i}\right.$;

C) $\operatorname{cov}\left(\varepsilon_{i}, D_{2}\right)=0 ; \operatorname{cov}\left(\varepsilon_{i}, T_{i}\right)=0$; e $\operatorname{cov}\left(\varepsilon_{i}, T_{i} D_{2}\right)=0$.

O item " $c$ " implica que o termo de erro não esteja correlacionado com outras variáveis na equação e representa o pressuposto da tendência paralela (common trends assumption), sendo uma condição forte do modelo.

Pela hipótese de tendência paralela admite-se que, na ausência do tratamento, tanto o grupo de tratamento quanto o de controle teriam seguido a mesma tendência. Entretanto, a mesma não é testável, já que não se pode observar o grupo de tratamento na ausência de tratamento. Embora não exista uma maneira de demonstrar se teriam seguido a mesma trajetória paralela caso não houvesse mudança de política, algumas evidências quanto à sua validade podem ser observadas.

Dessa forma, é necessário que os dois grupos sigam tendências iguais no tempo. Portanto, $\delta_{0}$, deverá ser comum aos dois, além do período de tempo ser o mesmo e dos fatores não observáveis específicos aos dois serem constantes no tempo.

$11 \quad$ Ver Meyer (1995). 
Conforme já mencionado, as empresas analisadas apresentavam dados de gastos positivos em PEBD nos períodos anteriores aos respectivos períodos de tratamento. Crespi et. al. (2011)Technology and Innovation Programs (STIP admitem que a comparação entre os grupos possa ser feita desde que os dados disponíveis para os períodos pré-tratamento de cada estimativa, no caso 2008 e 2011, mostrem igualdade de tendências. E, embora existam testes formais para isso, a necessidade de dados para períodos mais longos, na maioria das vezes, é um fator limitante.

Além disso, é possível que ocorram alterações em características observáveis entre um período e outro, o que poderia comprometer a tendência paralela. No entanto, deve-se ressaltar que, com a inclusão dos regressores adicionais no modelo, cuja omissão poderia estar causando viés nas estimativas, a hipótese da tendência paralela fica fortalecida. ${ }^{12}$

\subsection{Apoio à P\&D por meio de Incentivos Fiscais}

Na modalidade incentivos fiscais, destaca-se a Lei do Bem, Lei no 1.196/2005, como um primeiro movimento em direção a uma melhor adequação desse tipo de instrumento em relação aos anteriores, com base na Lei n ${ }^{\circ}$ 8.661/1993 (MATESCO; TAFNER, 1996). ${ }^{13}$

A Lei do Bem alcançou maior participação na estrutura de incentivos fiscais a partir de 2007, ampliando o acesso das empresas, apesar da predominância da Lei de Informática (ver Tabela 2).

Tabela 2 - Renúncia fiscal segundo as leis de incentivo à PEBD e capacitação tecnológica (em milhões de reais)

\begin{tabular}{cccccccc}
\hline Ano & $\begin{array}{c}\text { Lei de In- } \\
\text { formática }\end{array}$ & $\%$ & $\begin{array}{c}\text { Lei do- } \\
\text { Bem }^{15}\end{array}$ & $\%$ & Outros & $\%$ & Total \\
2006 & $2.038 .482,30$ & $76,55 \%$ & $227.859,40$ & $8,56 \%$ & $396.614,10$ & $14,89 \%$ & $2.662 .955,80$ \\
2007 & $2.755 .400,20$ & $70,10 \%$ & $868.455,20$ & $22,09 \%$ & $307.049,90$ & $7,81 \%$ & $3.930 .905,30$ \\
2008 & $3.261 .370,70$ & $60,80 \%$ & $1.582 .712,90$ & $29,50 \%$ & $520.427,10$ & $9,70 \%$ & $5.364 .510,70$ \\
2009 & $3.103 .252,00$ & $62,27 \%$ & $1.382 .758,00$ & $27,74 \%$ & $497.911,30$ & $9,99 \%$ & $4.983 .921,30$ \\
2010 & $3.570 .760,00$ & $61,46 \%$ & $1.727 .138,80$ & $29,73 \%$ & $512.114,90$ & $8,81 \%$ & $5.810 .013,70$ \\
2011 & $3.771 .520,00$ & $66,53 \%$ & $1.409 .983,90$ & $24,87 \%$ & $487.336,60$ & $8,60 \%$ & $5.668 .840,50$ \\
\hline
\end{tabular}

Fonte: Ministério da Ciência, Tecnologia e Inovação (MCTI, 2012)

12 Os fatores não observáveis são assumidos como invariáveis no tempo. Já os fatores observáveis são controlados.

13 Entre os programas, destacam-se o Plano de Desenvolvimento Tecnológico da Industria (PDTI) e o Plano de Desenvolvimento Tecnológico da Agropecuária (PDTA).

14 Leis $\mathrm{n}^{\circ} 8.248 / 1991$ e $^{\circ} 10.176 / 2001$.

15 Lei $n^{\circ} 11.196 / 2005$. 
Os montantes da renúncia fiscal são bem superiores às operações de financiamento, o que explica a elevada concentração de empresas beneficiárias de incentivos fiscais e, também, acaba concentrando os benefícios em poucas e grandes empresas, apesarde haver aumentado o acesso de menores empresas. ${ }^{16}$

\subsubsection{Apoio à P\&D via financiamentos}

A Tabela 3 apresenta um breve comparativo dos recursos financeiros públicos com as atividades de PËD. Apesar de mais significativos após 2005, nota-se que ainda foram menos de um terço, em média, comparados aos incentivos fiscais vistos na Tabela 2.

Tabela 3 - Recursos financeiros destinados às atividades de PEBD (em milhões de reais)

\begin{tabular}{|c|c|c|c|c|c|}
\hline Ano & Próprios & \multicolumn{1}{l|}{$\%$} & Públicos & \% & Total \\
\hline 2005 & 6.178 .70 & $94 \%$ & 422.20 & $6 \%$ & 6.600 .90 \\
\hline 2008 & 10.420 .85 & $89 \%$ & 1.269 .15 & $11 \%$ & 11.690 .00 \\
\hline 2011 & 11.428 .03 & $87 \%$ & 1.672 .38 & $13 \%$ & 13.100 .41 \\
\hline
\end{tabular}

Fonte: Pesquisa de Inovação (Pintec); IBGE (2005, 2007, 2010, 2013).

A Tabela 4 mostra a participação entre recursos públicos e privados, distribuídos em valores acompanhados dos respectivos percentuais, para cada grupo tecnológico em toda a indústria de transformação. Nota-se uma distribuição bastante desigual dos recursos públicos em PEBD predominando em todos os anos, com alta concentração nos setores de média-alta tecnologia. Os dados desagregados em termos percentuais para os setores mais intensivos em tecnologia (alta e média-alta) podem ser vistos na Tabela 5, na qual há maior clareza quanto à essa concentração. 


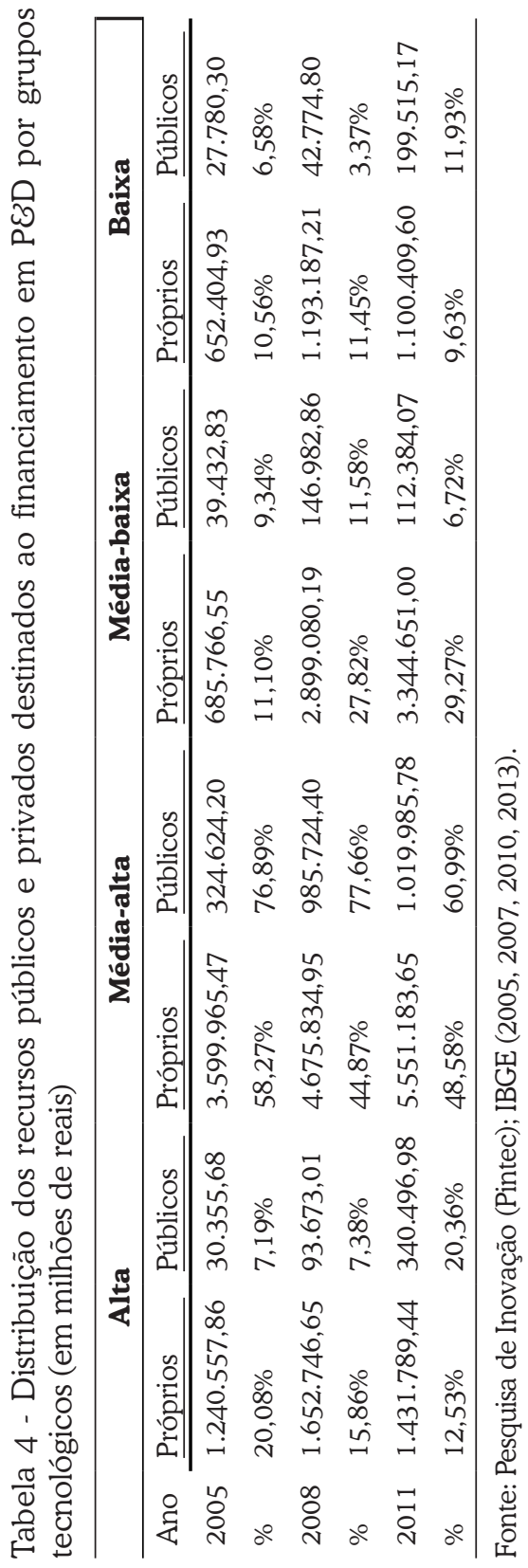

É possível observar, por exemplo, que os percentuais mais elevados concentraram-se na indústria automobilística, cujos ficaram acima de $40 \%$ até 2008. Entre 2009 e 2011, reduziu-se a participação da automobilística, ao mesmo tempo que 
a parcela relativa dos recursos públicos para o grupo de alta tecnologia elevou-se para $20,36 \%$. No interior deste, os percentuais setoriais mostraram maior participação dos financiamentos públicos para a informática e farmacêutica, possivelmente uma consequência dos programas setoriais específicos para esses setores.

Não obstante o aumento observado, os dados sugerem questionamentos a respeito da baixíssima participação dos setores de alta intensidade tecnológica e do suposto papel exercido por eles no âmbito das políticas industriais enquanto impulsionadores do desenvolvimento tecnológico. Os mesmos foram elencados como prioritários desde a Pitce e compunham a maioria dos programas setoriais do BNDES.

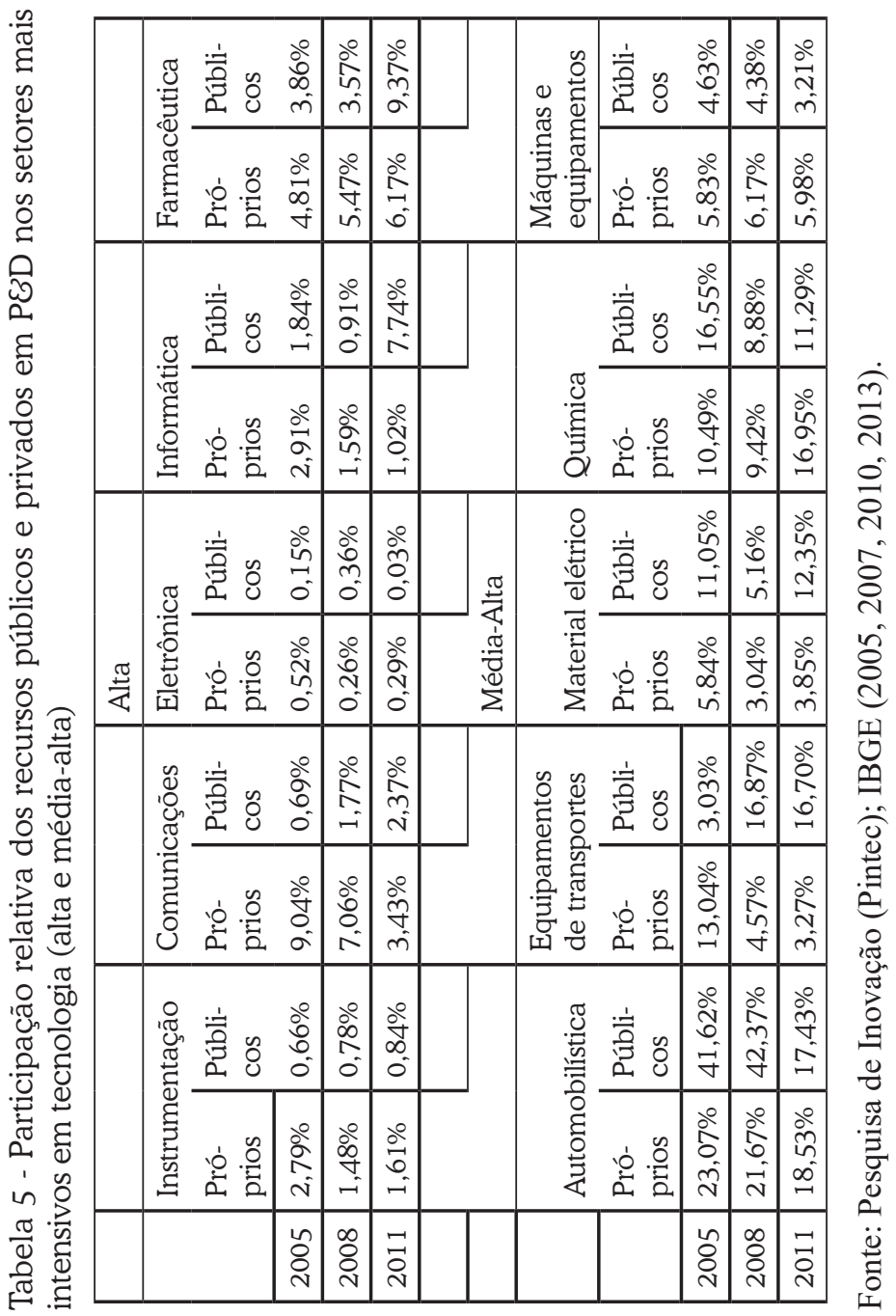


No entanto, até 2008, conforme se observa, o percentual alocado de financiamento público pouco excedeu $7 \%$, restando dúvidas se a baixa magnitude, em termos absolutos, do valor total alocado nesses setores seria suficiente para incentivar aumentos significativos de gastos empresariais em PEDD.

Conforme argumentado na introdução, e em decorrência de boa parte dos argumentos teóricos mencionados que explicam a possibilidade de ocorrência daqueles aumentos, os efeitos esperados dos recursos públicos nos setores de alta intensidade tecnológica podem diferir em relação aos outros.

\subsection{Caracterização das Empresas Beneficiárias e não Beneficiárias}

As estatísticas da descrevem as variáveis utilizadas, possibilitando comparações entre empresas beneficiárias e não beneficiárias de cada tipo de instrumento durante o período de análise. As mesmas referem-se à amostra inicial de onde foram constituídos os grupos de tratamento e de controle. 


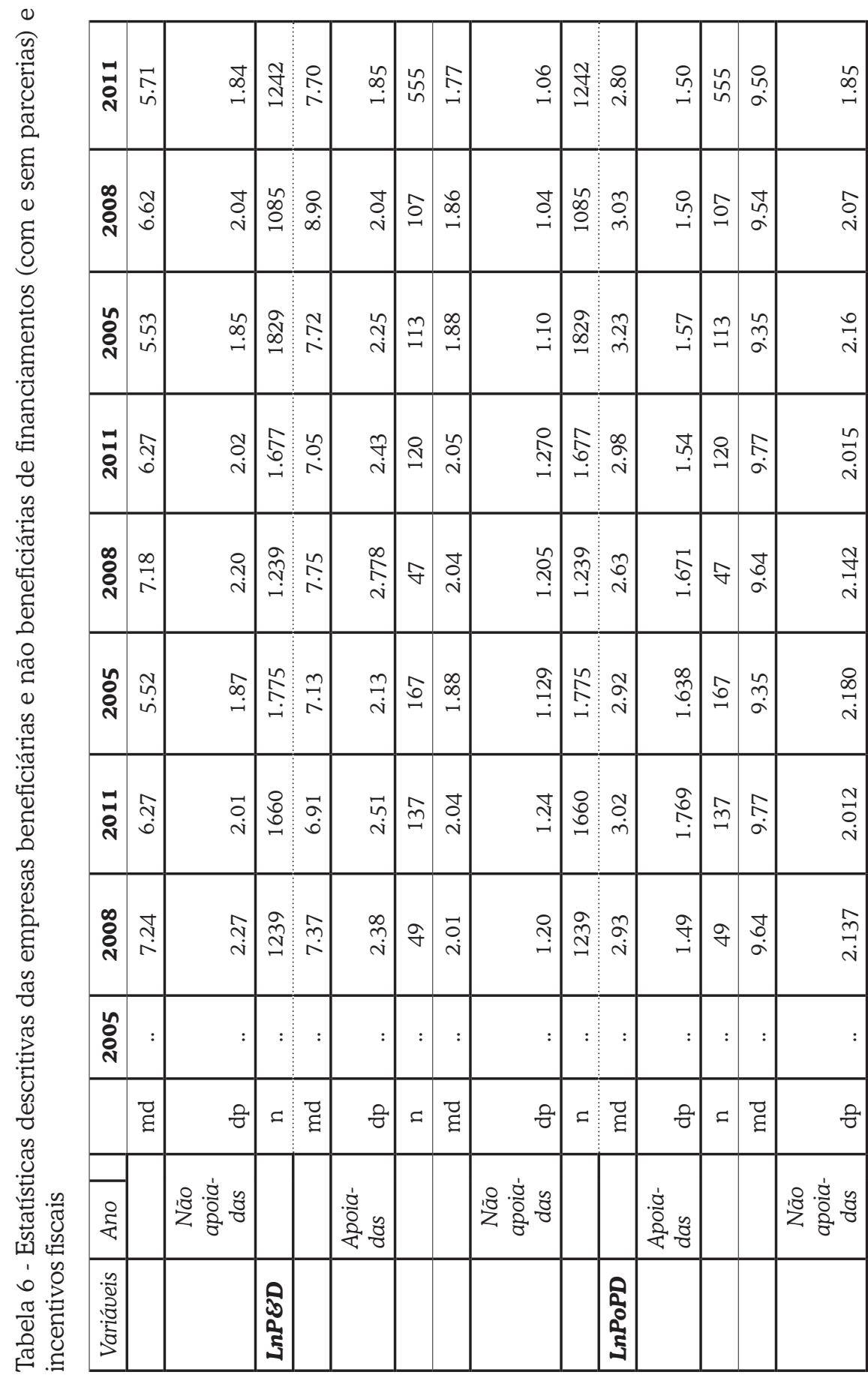




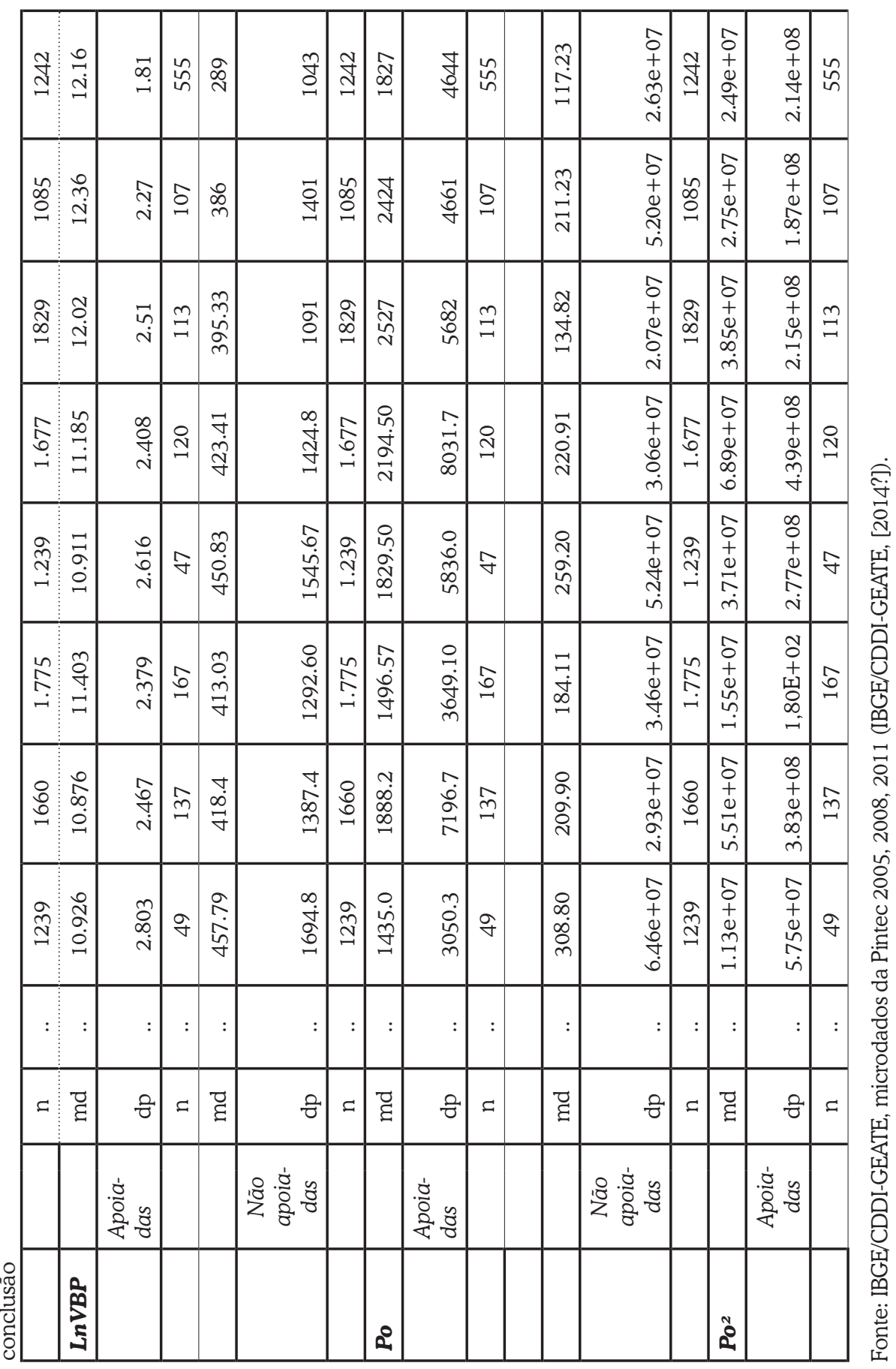


Nota-se que a maior intensidade de gastos em PEBD em favor das empresas beneficiárias é mais evidente no caso dos incentivos fiscais. É possível perceber que os resultados médios das covariadas são maiores para as empresas beneficiárias, com diferenças mais nítidas para as beneficiárias de incentivos fiscais, quando comparados aos financiamentos, refletindo um viés para as grandes empresas.

Os gastos aumentam de 2005 para 2008 para ambas as categorias, ano em que atingem valores máximos. No entanto, nota-se que a diferença entre os valores médios de intensidade de PEBD entre apoiadas e não apoiadas são bem inferiores para os dois tipos de financiamentos, quando comparados aos incentivos fiscais. Tal diferença, que para os financiamentos sem parcerias, em 2008, foi pouco expressiva (7.374-7.240) elevou-se em 2011 (6.911-6.270), ao mesmo tempo que se observa a maior frequência de empresas de maior porte entre as apoiadas, dada pelos valores médios da variável de tamanho $(P o)$.

A partir de 2008, com a PDP houve uma reorientação dos financiamentos, tanto da Finep quanto do BNDES, para novas áreas e setores considerados prioritários. Além disso, o programa Inova Brasil concentrou recursos em setores mais intensivos em PEBD enfatizando a criação dos programas setoriais. A maior diferença observada pode ser um reflexo dessas mudanças, captado nos dados de 2011.

O aumento no número de empresas que acessaram a Lei do Bem, a partir de 2007, verifica-se principalmente no período mais recente, em 2011. A diferença entre os valores médios de gastos em PËD entre apoiadas e não apoiadas é bem expressiva para todos os períodos. Além disso, são bem superiores quando comparadas aos financiamentos, refletindo, entre outras características, tamanhos maiores de empresas, conforme se vê nas médias até 2008. Em 2011, com o maior número de apoiadas, houve uma redução da média e, com isso, a diferença de gastos, talvez como reflexo da maior participação de empresas de menor porte.

A queda nos valores médios da intensidade de PEBD possivelmente reflete os efeitos da conjuntura pós-crise de 2008. Sabe-se que as oscilações de mercado afetam as decisões de inovação das empresas e, portanto, os investimentos em PEDD. Assim, não seria incorreto imaginar que o cenário de instabilidade surgido com a crise de 2008 teria influenciado o comportamento empresarial, gerando revisões e/ou adiamentos das decisões de investimentos de maior risco,pois, naquele contexto, apesar da recuperação econômica em 2010, o ano de 2011 registrou forte queda de $8,7 \%$ do valor adicionado da indústria de transformação em relação a $2008 \cdot{ }^{17}$

17 Pesquisa de Inovação 2011 (IBGE, 2013). 


\section{Resultados}

Nas estimativas, a amostra foi subdividida em grupos tecnológicos e os resultados sugerem que a resposta das empresas aos estímulos dos instrumentos de suporte público variam conforme a intensidade tecnológica. Isso é válido para cada tipo específico de instrumento.

No caso dos incentivos fiscais, no período 2005-2008 não houve efeitos significativos em nenhum dos grupos para os quais se aplicou o modelo. Isso implica que a diferença de gastos em PẺD de 2008 em relação a 2005 para as empresas beneficiárias em relação às não beneficiárias não foi significativa. Os efeitos positivos restringiram-se aos grupos de baixa e média-alta tecnologia e mantiveram-se no período seguinte (2008-2011), quando, então, os efeitos ganharam significância (ver Tabela 7). 


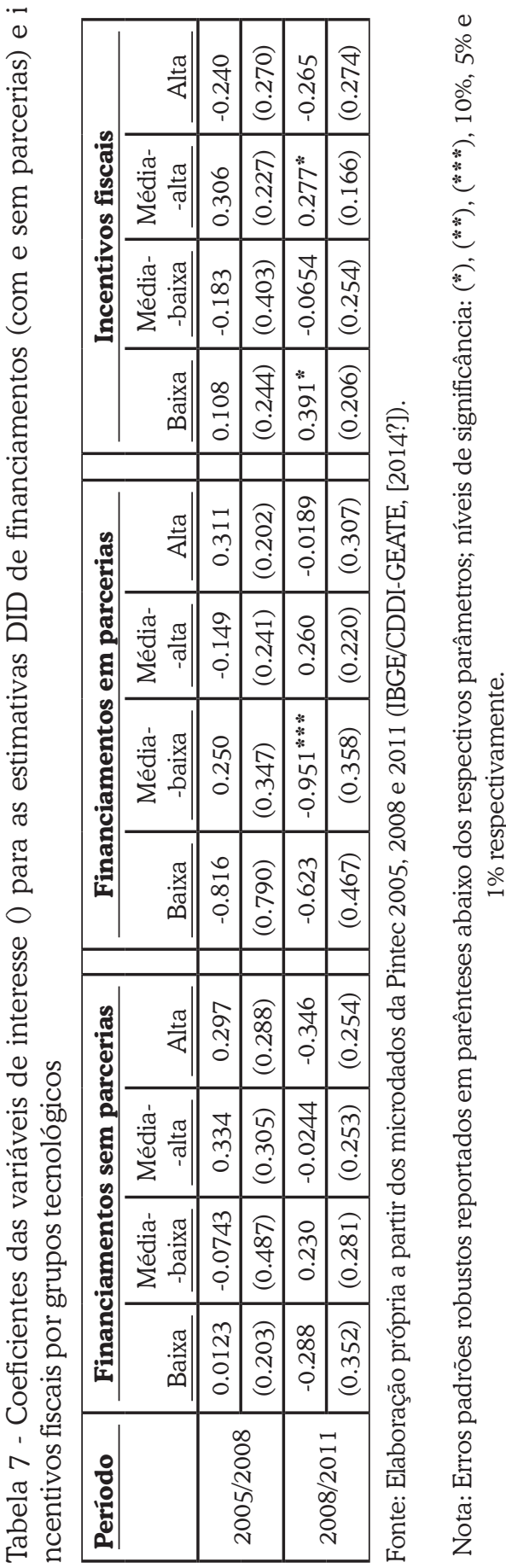


Já no caso dos financiamentos, seja em parcerias ou não, não houve efeitos positivos e significativos em nenhum dos períodos analisados, seja para os quatro grupos tecnológicos, ou para cada uma das duas estimativas realizadas. Isso implica não ser possível afirmar que esses instrumentos levaram as empresas beneficiárias a aumentar de forma significativa seus gastos em PEDD, tanto de 2005 para 2008, quanto de 2008 para 2011, quando comparadas às não beneficiárias.

No segundo painel das estimativas para os financiamentos em parcerias (2008-2011), nota-se que somente para o grupo de média-baixa tecnologia o coeficiente de apresentou significância e elevada magnitude, porém foi negativo, evidenciando efeito substituição. A maioria das estimativas feitas para esse período exibiu efeitos negativos, e esse comportamento predominante pode ser um sinal de que, embora a maioria dos setores não tenha feito substituição dos recursos privados pelos recursos públicos, é possível que estes últimos contribuíram para reduzir os gastos em PËD.

Do ponto de vista dos financiamentos, não se verificam efeitos positivos e significativos, e, quanto aos incentivos fiscais, conforme reportado nas estimativas de 2008-2011, a ocorrência de crowd in restringiu-se aos grupos de baixa tecnologia e de média-alta, sendo mais pronunciados nos primeiros.

Em ambas as modalidades, as estimativas realizadas permitem concluir que, embora haja elevada concentração dos incentivos fiscais na estrutura de suporte público do país, seus efeitos são limitados, não sendo permanentes ao longo do tempo.

Tal fato corrobora o estudo de García-Quevedo e Calleron (2005), que chegam à conclusão de que não existe necessária correspondência entre o esforço privado e suporte público. A preponderância daqueles incentivos não implica, necessariamente, maiores esforços privados pelas empresas beneficiárias. Ao mesmo tempo, deve ser lembrado que a estrutura industrial do país caracteriza-se pelo maior peso de setores menos intensivos em PËD, embora haja alta participação do setor de média-alta, sobretudo em decorrência do setor automobilístico.

Assim, conforma-se uma tendência de apoio às grandes empresas em setores com maior participação no valor adicionado da indústria de transformação em detrimento do setor de alta intensidade tecnológica. No entanto, o aumento contínuo de gastos em P\&D no último depende, conforme aponta Coccia (2012), da contínua mobilização, sustentação e alocação de recursos públicos. Dessa forma, dadas as características da estrutura industrial, dificulta-se a alocação contínua para aqueles de maior intensidade, revelando um desafio às políticas.

Diante desse resultado, a maior discricionariedade dos financiamentos e possíveis efeitos esperados no sentido de melhor viabilizar as intenções alocativas das políticas, apontada por Montmartin e Herrera (2014), não se confirma nas estimativas.

A literatura recente destaca que a reação aos estímulos dos incentivos fiscais nas empresas menos intensivas possivelmente seria mais forte quando comparada 
aos setores mais intensivos, porque elas direcionam menores parcelas da receita à PED. Aassim, um mesmo montante de incentivos fiscais levaria a uma maior variação nos gastos em PẺ em relação aos setores mais intensivos (CASTELLACCI; LIE, 2013).

De forma inversa, setores em que as oportunidades tecnológicas são mais elevadas tendem a ser menos sensíveis às influências do suporte público, pois os desafios tecnológicos que existem para eles são mais intensos, e as mudanças ocorrem em maior velocidade, requerendo a manutenção de volumes expressivos de gastos (LEE, 2011). Isso implica que os estímulos necessários para elevarem seus gastos em níveis expressivamente superiores aos que já realizam normalmente exige montantes igualmente expressivos de incentivos fiscais. Tal fato corrobora a hipótese de que o grau de intensidade tecnológica condiciona os efeitos esperados pelo suporte público sobre os gastos privados em P\&BD.

Outro aspecto relevante é que em nenhum dos grupos houve concomitância entre os efeitos positivos e significativos dos dois tipos de instrumentos. Isso pode ser um indício de que a disponibilidade de um mix de instrumentos mais diversificado para o apoio à PEBD no país, e que procurou atingir um conjunto mais variado de empresas, não necessariamente teria resultado em uma combinação eficaz entre eles.

Embora as políticas públicas da década procuraram incrementar o mix de instrumentos, a combinação eficaz dependeria de como cada setor reage aos estímulos, sendo tais reações diferenciadas entre eles. O mix adequado entre incentivos fiscais e financeiros não resultaria em efeito substituição, gerado por cada um, nem em efeito neutro, entre eles.

As análises da literatura internacional que procuram avaliar o impacto de políticas considerando características setoriais ainda são escassas e limitadas a comparações entre vários países (LEE, 2011; BODAS; FREITAS et al., 2017).

Os resultados encontrados neste artigo coincidem, em alguns aspectos, com essa literatura, havendo necessidade de um maior aprofundamento das pesquisas no Brasil.

\section{Considerações Finais}

O presente artigo avaliou os efeitos dos incentivos fiscais e dos financiamentos públicos sobre os gastos empresariais em PEBD no contexto de retorno das políticas de incentivo à inovação e PED durante os anos 2000. Naquele momento, a inovação tecnológica inseriu-se na agenda de políticas, reconhecendo-se a insuficiência dos níveis de gastos empresariais em PËD como um indício do caráter pouco inovador da indústria brasileira. 
Lançaram-se vários programas, e, dado o maior montante de recursos públicos, esperava-se um incremento dos gastos privados em PED. Um aspecto conjuntural favorável a essa expectativa foi a concomitância dessas políticas com a retomada do crescimento econômico a partir de meados da década.

Nessas condições, a questão é saber se os instrumentos acionados foram capazes de promover aumentos nos gastos privados ou se levaram somente à substituição dos recursos privados pelos públicos, não elevando a intensidade de gastos em PEBD pelas empresas.

O quadro teórico sobre o problema da eficácia dos instrumentos atribui as falhas de mercado como um dos obstáculos que impedem os investimentos em PEBD de atingirem níveis suficientemente elevados. Questões como apropriabilidade incompleta dos retornos de PEBD e imperfeições nos mercados de capitais são algumas dessas falhas e que justificariam a intervenção das políticas (ARROW, 1962; NELSON, 1959). O crédito subsidiado e os incentivos fiscais corrigiriam tais falhas, supostamente levando os investimentos em PEBD aos níveis desejados.

Porém, ainda não há consenso na literatura quanto à eficácia dos instrumentos. Um dos problemas é que a sua concessão não ocorre de forma aleatória, tornando os resultados das avaliações fortemente sujeitos ao problema do viés de seleção nas estimativas. A fim de amenizar tal problema, o modelo proposto baseou-se no método de regressão DID com covariadas, definindo-se a intensidade de gastos em PEB como variável dependente. Considerou-se a hipótese de haver relações entre a intensidade tecnológica setorial e os efeitos de cada tipo específico de instrumento de apoio.

As variáveis de interesse foram construídas a partir da interação entre dummies anuais e dummies para cada tipo específico de instrumento de apoio: financiamentos em parcerias, financiamentos sem parcerias e incentivos fiscais. O coeficiente dessa variável de interação mensurou, portanto, os impactos de cada instrumento, possibilitando comparar se os gastos em PEBD das empresas beneficiárias variam de forma significativa, e positiva, em relação às não beneficiárias.

Nesse ponto cabe uma ressalva. A literatura internacional sobre políticas de inovação e PËD emprega o método DID em avaliações de programas públicos que utilizam instrumentos de apoio como financiamentos e incentivos fiscais. $\mathrm{Na}$ maioria dos casos, a avaliação de impacto de um tipo específico de instrumento representa, em geral, apenas uma determinada política ou um programa específico de apoio público. Dessa forma, o método se torna adequado para captar efeitos posteriores a uma mudança exógena de política. Nesse sentido, vale ressaltar que a avaliação de impactos dos instrumentos específicos feita neste estudo não se restringiu a apenas uma determinada política ou programa, já que as dummies indicam participações de empresas em vários programas, porém diferenciando apenas o instrumento utilizado. 
Conforme demonstrado, a partir de meados dos 2000 houve maior volume de recursos públicos direcionado aos financiamentos e incentivos fiscais nos diversos programas de apoio à PEBD. Simultaneamente, aumentou o número de empresas beneficiárias e, ao mesmo tempo, lançaram-se novos programas de apoio à $\mathrm{P} \mathrm{D}^{18}$ e inovação. Entretanto, eles ocorreram ao longo de todo o período da análise, ou seja, de forma contínua,não sendo, portanto, uma alteração única e exógena de políticas, como costumam ser os casos mais frequentes em que se aplicam o método DID.

Reconhece-se, assim, que resultados mais robustos seriam possíveis caso houvesse disponibilidade de dados permitindo: a) analisar os efeitos dos instrumentos utilizados em cada programa de apoio individual; b) verificar os impactos a partir do montante de financiamentos ou incentivos fiscais; e c) demonstrar que o aumento de recursos públicos destinados a essas duas modalidades no âmbito dos diversos programas de apoio à PẺD de fato caracterizaram mudanças de políticas. Porém, tal abordagem fica impossibilitada pela base de microdados da Pintec.

Conforme dito, o intuito do apoio público à PED é viabilizar a redução dos riscos associados à inovação e dos custos intrinsecamente ligados à natureza da PEBD.

Para que ocorram tais efeitos atenuantes, os valores necessários para levar as empresas a aumentar seus recursos próprios nas atividades de PËD diferem conforme a intensidade tecnológica de cada setor. Assim, os resultados esperados eram de que os efeitos, tanto dos incentivos fiscais, quanto dos financiamentos, variassem conforme o setor. De acordo com os resultados encontrados, os efeitos significativos e positivos restringiram-se somente aos incentivos fiscais, o que pode ser consequência da própria estrutura de apoio à PẺD no Brasil, tradicionalmente voltada para tais instrumentos, conforme demonstrado na seção 3.2.

Apesar do maior montante de recursos alocados para o financiamento à PEBD, sobretudo após 2005, os recursos públicos alocados foram bem inferiores aos da renúncia fiscal. Essa característica leva a supor que os valores necessários para gerar os estímulos atrativos ao setor privado de forma a elevar o retorno esperado em projetos mais arrojados de $\mathrm{P} \mathcal{E} \mathrm{D}$ foram insuficientes.

Tal insuficiência é o motivo que impediria as empresas de aportarem uma quantidade maior de recursos próprios em relação aos projetos que habitualmente constam em suas carteiras, tendo como resultado o não surgimento de efeitos de adicionalidade significativos.

No caso dos incentivos fiscais, notaram-se efeitos diferenciados para os grupos de baixa tecnologia e média-alta, sendo mais fortes nos primeiros, podendo ser uma evidencia de que empresas mais intensivas em tecnologia não necessariamente produzem resultados mais eficazes quanto ao uso de recursos públicos.

18 Sendo a Lei do Bem o exemplo mais notório dessa última modalidade. 
Entre as limitações desta análise, aponta-se que está restrita somente a um método de estimação. Portanto, seria conveniente testar os instrumentos através de outros métodos a fim de se verificar o comportamento de cada um.

Ao mesmo tempo, conforme apontado na revisão, um aspecto positivo em relação aos estudos anteriores baseados somente na Pintec foi a possibilidade de aplicar um painel em dois períodos, acompanhando-se as mesmas empresas que foram beneficiárias no período atual e não foram no período anterior. Por outro lado, isso reduziu o tamanho da amostra, gerando poucas observações, sobretudo nos setores com baixa participação na estrutura industrial, como é o caso do setor de alta tecnologia.

Além disso, nem sempre foi possível obter as mesmas variáveis para o conjunto de empresas selecionado em cada grupo tecnológico, o que também resultou amostras reduzidas. Com a continuidade e divulgação da Pintec para os próximos anos, espera-se um aumento na amostra de empresas, o que permitirá, nos estudos futuros, combinar outras técnicas de estimação comparando-se empresas de características similiares, como matching, por exemplo, e alongando-se o período de análise.

\section{Referências}

ARAUJO, B. C. Incentivos fiscais à pesquisa e desenvolvimento e custos de inovação no Brasil. [S.1.]: IPEA, 2010. p. 3-11. Nota Técnica Diretoria de Estudos e Políticas Setoriais de Inovação, Regulação e Infraestrutura (DISET).

ARROW, K. Economic welfare and the allocation of resources for invention. In: BUREAU, U.-N. (ed.). The rate and direction of inventive activity: economic and social factors. Nova Jersey: Princeton University Press, 1962. v. 1, p. 609-626.

ASCHHOFF, B. The effect of subsidies on RED investment and success: do subsidy history and size matter? ZEW Discussion Papers, n. 09-032, 2009.

AVELLAR, A. P. Avaliação de políticas de fomento à inovação no Brasil : impacto dos incentivos fiscais e financeiros em 2003. 2007. Tese (Doutorado) - Instituto de Economia, Universidade Federal do Rio de Janeiro, 2007.

AVELLAR, A. P.; BOTELHO, M. R. Políticas de apoio à inovação em pequenas empresas: evidências sobre a experiência brasileira recente. Economia e Sociedade Unicamp, v. 24, n. 2(54), p. 379-417, 2015.

BASTOS, V. D. Fundos públicos para ciência e tecnologia. Revista do BNDES, v. 10, n. 20, p. 229-260, 2003.

BODAS FREITAS, I. et. al. Sectors and the additionality effects of RED tax credits : a crosscountry microeconometric analysis. Research Policy, v. 46, n. 1, p. 57-72, 2017. 
BRASIL. Relatório de macrometas (PDP). São Paulo: Abimaq. Disponível em: http://www. abimaq.org.br. Acesso em: 12 dez. 2019.

BUISSERET, T. J.; CAMERON, H. M.; GEORGHIOU, L. What difference does it make? Additionality in the public support of RED in large firms. International Journal of Technology Management, v. 10, n. 4/5/6, 1995.

CARVALHO, A. Why are tax incentives increasingly used to promote private RED ? CEFAGEWorking Paper, v. 4, p. 02-22, 2011.

CASTELLACCI, F.; LIE, C. Do the effects of RED tax credits vary across industries? A metaregression analysis. Munich Personal RePEc Archive, n. 47937, 2013.

CGEE/ANPEI. Os novos instrumentos de apoio à inovação: uma avaliação inicial. Brasília: CGEE, 2009.

COCCIA, M. Political economy of RED to support the modern competitiveness of nations and determinants of economic optimization and inertia. Technovation, v. 32, n. 6, p. 370-379, 2012.

COHEN, W. Fifty years of empirical studies of innovative activity and performance. Amsterdam: Elsevier, 2010. v. 1.

CORDER, S. Economia e tecnologia. Revista Economia e Tecnologia-Universidade Federal do Paraná, v. 14, n. 04, p. 87-100, 2008.

CRESPI, F.; QUATRARO, F. Technological forecasting $\mathcal{E}$ social change systemic technology policies : issues and instruments. Technological Forecasting $\mathcal{E}$ Social Change, v. 80, n. 8, p. 1447-1449, 2013.

CRESPI, G. et al. Evaluating the impact of science, technology and innovation programs: a methodological toolkit. [S.1.]: BID, 2011. p. 88.

CZARNITZKI, D.; ALMUS, M. The effects of public RED subsidies on firms' innovation activities: the case of Eastern Germany. ZEW Discussion Papers. n.1-10, 2002.

CZARNITZKI, D.; HUSSINGER, K. The link between RED subsidies , spending and technological performance. Discussion Paper-Center for European Economic Research - ZEW, No. 04-56, 2004.

CZARNITZKI, D.; KRAFT, K. An empirical test of the asymmetric models on innovative activity: who invests more into RED, the incumbent or the challenger? Journal of Economic Behavior $\mathcal{E}$ Organization, v. 54, n. 2, p. 153-173, 2004.

DAVID, P.; HALL, B. H.; TOOLE, A. Is public RED a complement or substitute for private REZD? A review of the econometric evidence. Research Policy, v. 29, n. 4-5, p. 497-529, 2000.

DE NEGRI, J. A., DE NEGRI, F.; LEMOS, M. B. O impacto do programa FNDCT sobre o desempenho e o esforço tecnológico das empresas industriais brasileiras. In: DE NEGRI, J. A.; KUBOTA, L. C. Políticas de incentivo à inovação tecnológica no Brasil. Brasília: IPEA, 2008. 
DIMOS, C.; PUGH, G. The effectiveness of RED subsidies: a meta-regression analysis of the evaluation literature. Research Policy, v. 45, n. 4, p. 797-815, 2016.

DUFLO, E.; BERTRAND, M.; MULLANINATHAN, S. How much should we trust differences in differences. NBER Working Paper, n. 8841, 2002.

CALLEJÓN, M.; GARCÍA-QUEVEDO, J. Public subsidies to business REBD : do they stimulate private expenditures? Environment and Planning C, v. 23, n. 2, p. 279-293, 2005.

HALL, B. H.; LERNER, J. The financing of RED and innovation. In: HALL, B. H.; ROSENBERG, N. Handbook of the economics of innovation. Oxford: North-Holland, 2010.

HECKMAN, J. J. Sample Selection bias as a specification error. Econometrica, v. 47, n. 1, p. 153-161, 1979.

IBGE. CDDI-GEATE- Centro de Documentação e Disseminação de Informações/Gerência de Atendimento-Sala de Sigilo. [Rio de Janeiro, 2014?]. Dados acessados nos anos de 2014 e 2015.

IBGE. Instituto Brasileiro de Geografia e Pesquisa. Pesquisa de inovação-PINTEC. Rio de Janeiro, 2002. Disponível em: https://biblioteca.ibge.gov.br/index.php/bibliotecacatalogo?view $=$ detalhesEid $=282639$. Acesso em: 12 dez. 2019 .

IBGE. Instituto Brasileiro de Geografia e Pesquisa. Pesquisa de inovação-PINTEC. Rio de Janeiro, 2007. Disponível em: https://biblioteca.ibge.gov.br/index.php/bibliotecacatalogo?view $=$ detalhesEid =282639. Acesso em: 12 dez. 2019.

IBGE. Instituto Brasileiro de Geografia e Pesquisa. Pesquisa de inovação-PINTEC. Rio de Janeiro, 2005. Disponível em: https://biblioteca.ibge.gov.br/index.php/bibliotecacatalogo?view $=$ detalhesEid $=282639$. Acesso em: $12 \mathrm{dez} .2019$.

IBGE. Instituto Brasileiro de Geografia e Pesquisa. Pesquisa de inovação-PINTEC. Rio de Janeiro, 2013. Disponível em: https://biblioteca.ibge.gov.br/index.php/bibliotecacatalogo?view $=$ detalhesEid $=282639$. Acesso em: $12 \mathrm{dez} .2019$.

IBGE. Instituto Brasileiro de Geografia e Pesquisa. Pesquisa de inovação-PINTEC. Rio de Janeiro, 2005. Disponível em: https://biblioteca.ibge.gov.br/index.php/bibliotecacatalogo?view $=$ detalhesEid $=282639$. Acesso em: 12 dez. 2019.

KANNEBLEY JR., S.; PORTO, G. Incentivos fiscais à pesquisa, desenvolvimento e inovação no Brasil: uma avaliação das políticas recentes. Documento para Discussão - BID, n. 236, 2012.

LACH, S. Do RED subsidies stimulate or displace private RED? Evidence from Israel. The Journal of Industrial Economics, 2002.

LEE, C.-Y. The differential effects of public RED support on firm RED: theory and evidence from multi-country data. Technovation, v. 31, n. 5-6, p. 256-269, 2011.

MARINO, M. et al. Additionality or crowding-out? An overall evaluation of public RED subsidy on private RED expenditure. Research Policy, 2016. 
MATESCO, V. R.; TAFNER, P.; GOMES, G. M. O estímulo aos investimentos tecnológicos : o impacto sobre as empresas brasileiras. Texto para Discussão - Instituto de Pesquisas Aplicadas, n. 429, 1996.

MCTI. Relatório anual da utilização de incentivos fiscais. Relatórios anuais, 2012. Disponível em: http://www.mct.gov.br/index.php/content/view/9252.html. Acesso em: 20 dez. 2015.

MEYER, B. D. Natural and quasi-experiments in economics. Journal of Business 8 Economic Statistics, v. 13, n. 2, p. 151, 1995.

MONTMARTIN, B.; HERRERA, M. Internal and external effects of RED subsidies and fiscal incentives : empirical evidence using spatial dynamic panel models. GREDEG Working Papers Series, n. 9, 2014. Disponível em: http://www.gredeg.cnrs.fr/working-papers.html. Acesso em: 10 dez. 2019.

NELSON, R. The simple economics of basic scientific research. Journal of Political Economy, v. 67, n. 3, p. 297-306, 1959.

OECD. Tax incentives for research and development: trends and issues. France: OECD, 2002. Disponível em: http://www.oecd.org/science/inno/2498389.pdf. Acesso em: 12 dez. 2019.

PACHECO, C. A. O financiamento do gasto em PEDD do setor privado no Brasil e o perfil dos incentivos. Revista USP, n. 89, p. 256-276, 2011.

PACHECO, C. A.; CORDER, S. Mapeamento institucional e de medidas de política com impacto sobre a inovação produtiva e a diversificação das exportações. Documento de Proyecto - CEPAL, n. 293, 2010.

POTTELSBERGHE, B.V.; NYSTEN, S.; MAGALLI, E. Evaluation of current fiscal incentives for business RED in Belgium. Brussels: Solvay Business School and Service Public Federal de Programmation Politique Scientifique, 2003 SHIMADA, E. Efetividade da Lei do Bem no estímulo ao investimento em P\&D: uma análise com dados em painel. 2014. Tese (Doutorado) - Universidade de São Paulo, 2014.

SHIMADA, E. Efetividade da Lei do Bem no estímulo ao investimento em P\&D: uma análise com dados em painel. 2014. Tese (Doutorado) - Universidade de São Paulo, 2014.

TAVARES, J. M. H. O papel do BNDES no financiamento da inovação tecnológica. 2012. Dissertação (Mestrado) - Universidade Federal do Rio de Janeiro, 2012. p. 3-8. TAVARES, J. M. H. O papel do BNDES no financiamento da inovação tecnológica. 2012. Dissertação (Mestrado) - Universidade Federal do Rio de Janeiro, 2012. p. 3-8.

WENDT, N. B. H. RED policy and firm heterogeneity : an analysis of the Norwegian tax-credit Scheme SkatteFUNN. 2014. Dissertação (Mestrado) - Faculdade de Ciências Sociais, Universidade de Oslo, 2014.

WOOLDRIDGE, J. Introdução à econometria: uma abordagem moderna. São Paulo: Cengage Learning, 2011. 


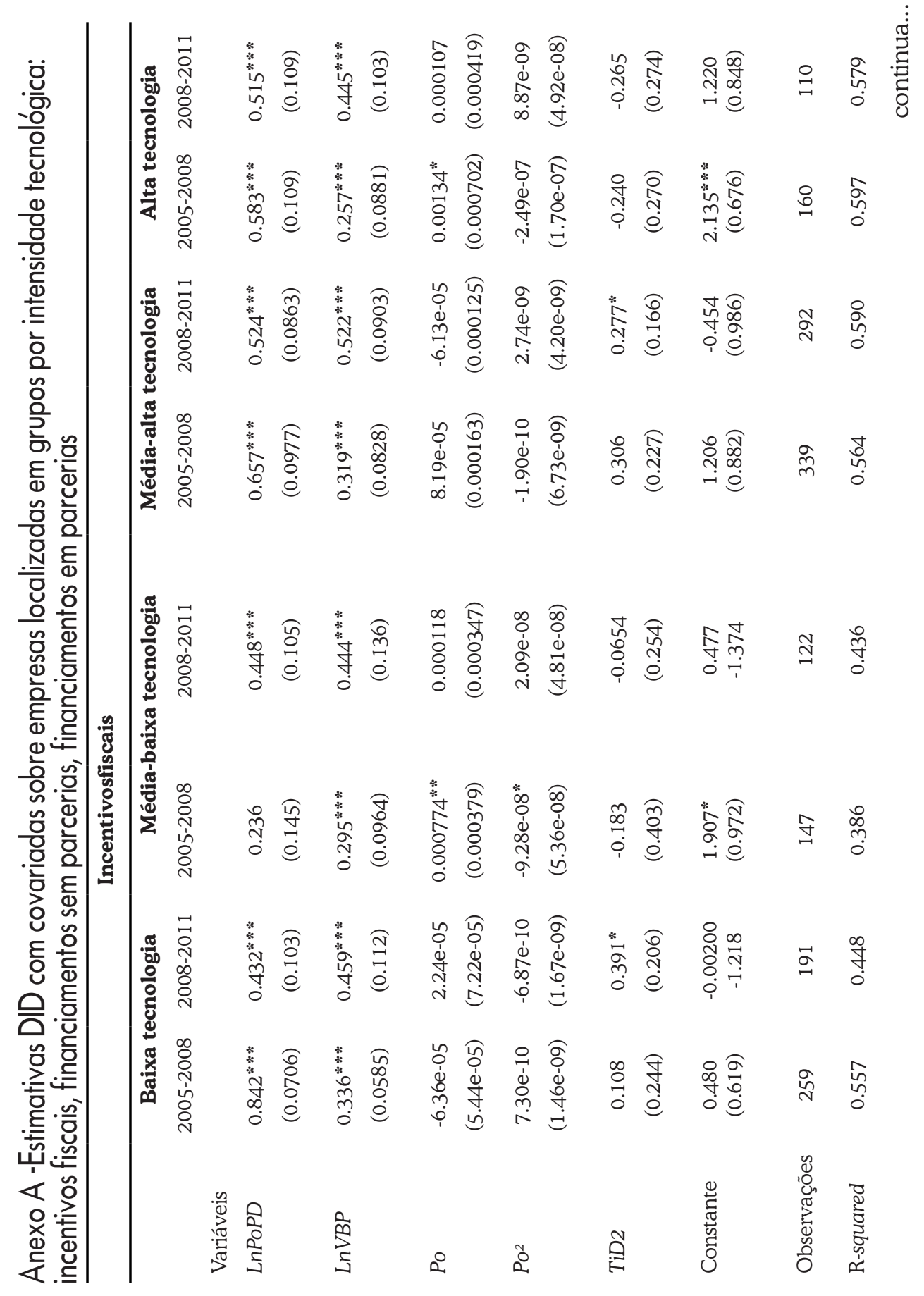




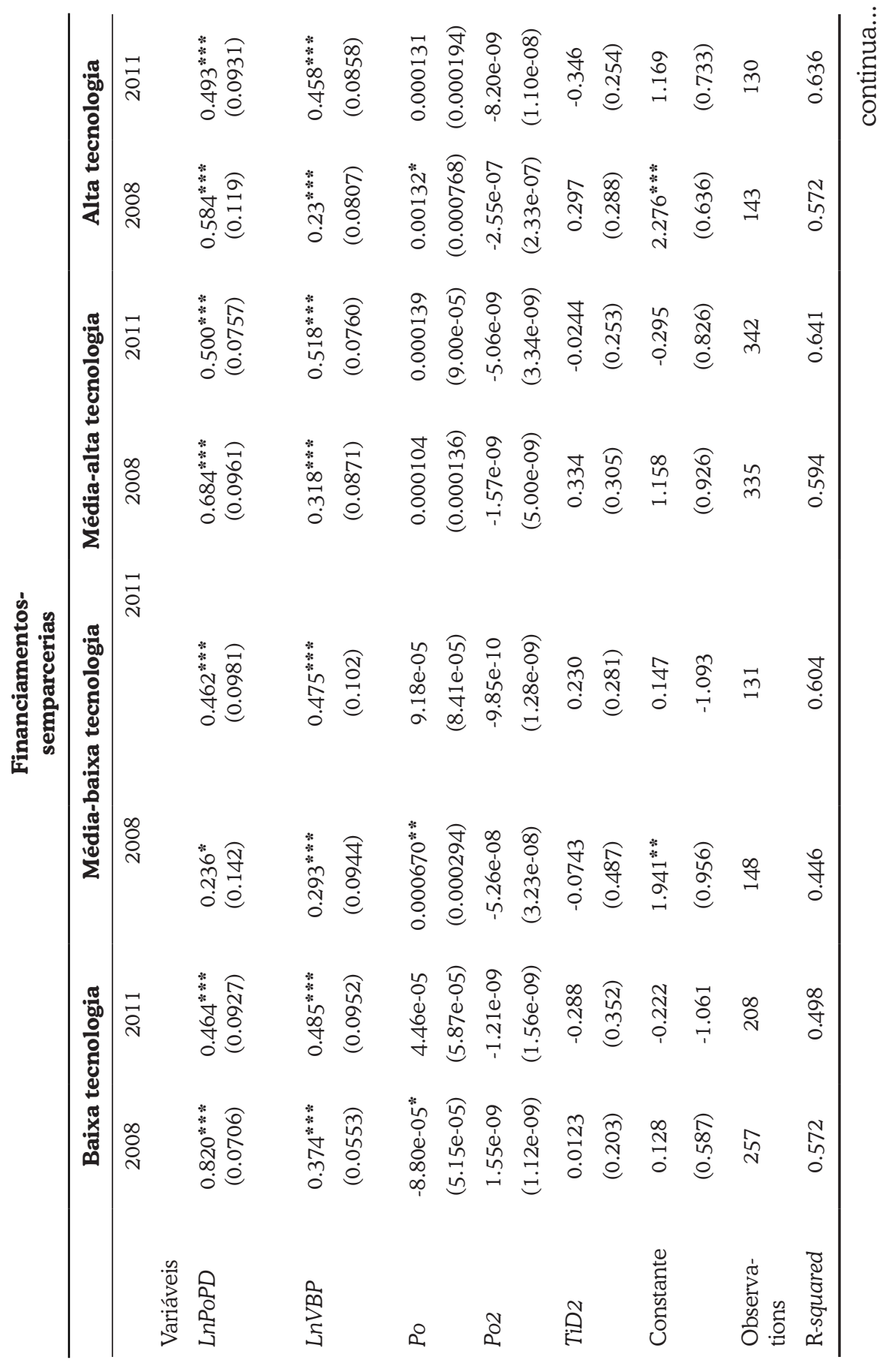




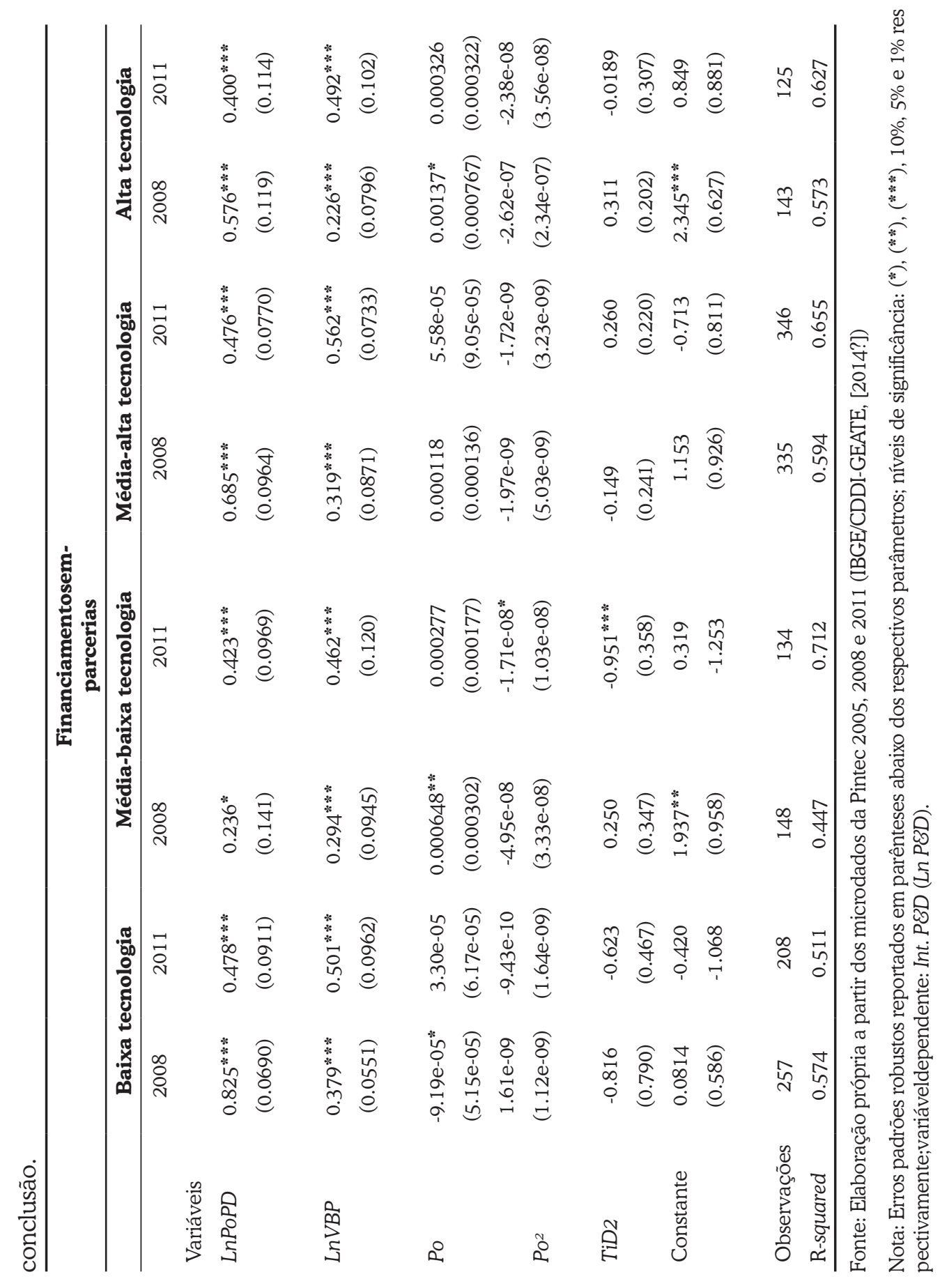


Recebido em: 04/09/2017. Aceito em: 07/08/2018.

(cc) BY 